\title{
Measurement of Martian boundary layer winds by the displacement of jettisoned lander hardware
}

\section{Paton, M.D.}

2018-07-15

Paton , M D , Harri , A-M \& Savijärvi , H 2018 , ' Measurement of Martian boundary layer winds by the displacement of jettisoned lander hardware ' , Icarus , vol. 309 , pp. 345-362 . https://doi.org/10.1016/j.i

http://hdl.handle.net/10138/313452

https://doi.org/10.1016/j.icarus.2018.03.020

cc_by_nc_nd

acceptedVersion

Downloaded from Helda, University of Helsinki institutional repository.

This is an electronic reprint of the original article.

This reprint may differ from the original in pagination and typographic detail.

Please cite the original version. 


\section{Accepted Manuscript}

Measurement of Martian boundary layer winds by the displacement of jettisoned lander hardware

M.D. Paton, A.-M. Harri, H. Savijärvi

PII: S0019-1035(17)30470-0

DOI: 10.1016/j.icarus.2018.03.020

Reference:

YICAR 12849

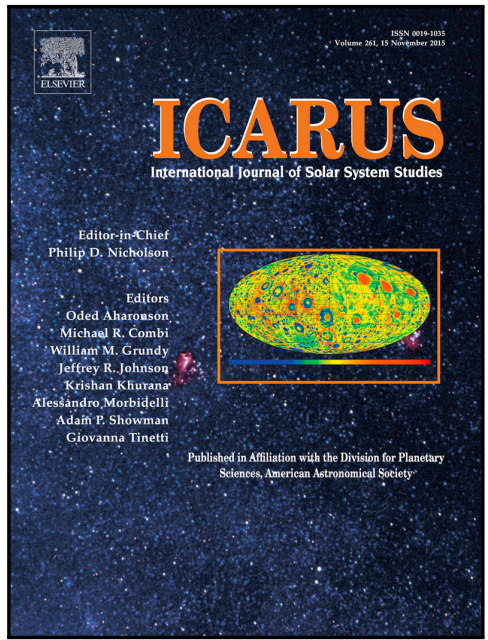

To appear in:

Icarus

Received date:

28 June 2017

Revised date:

10 December 2017

Accepted date:

19 March 2018

Please cite this article as: M.D. Paton, A.-M. Harri, H. Savijärvi, Measurement of Martian boundary layer winds by the displacement of jettisoned lander hardware, Icarus (2018), doi: 10.1016/j.icarus.2018.03.020

This is a PDF file of an unedited manuscript that has been accepted for publication. As a service to our customers we are providing this early version of the manuscript. The manuscript will undergo copyediting, typesetting, and review of the resulting proof before it is published in its final form. Please note that during the production process errors may be discovered which could affect the content, and all legal disclaimers that apply to the journal pertain. 


\section{Highlights}

- Ten unique wind measurements within the Martian PBL during lander descents

- Wind measurements from displacement of Beagle 2 and Schiaparelli jettisoned hardware

- Information on the structure of the PBL from Viking landers, Phoenix and Curiosity

- Phoenix lander experienced unusually high winds during landing

- Wind direction measurements correlate well with Mars Climate Database 


\title{
Measurement of Martian boundary layer winds by the displacement of jettisoned lander hardware
}

\author{
M. D. Paton ${ }^{\mathrm{a}, * *}$, A. -M. Harria ${ }^{\mathrm{a}}$ H. Savijärvi ${ }^{\mathrm{b}}$ \\ ${ }^{a}$ Finnish Meteorological Institute, PO Box 503, FIN-00101 Helsinki, Finland \\ ${ }^{b}$ Department of Physics, University of Helsinki, FI-00560, Finland
}

Abstract
Martian boundary layer wind speed and direction measurements, from a variety of locations, seasons and times, are provided. For each lander sent to Mars over the last four decades a unique record of the winds blowing during their descent is preserved at each landing site. By comparing images acquired from orbiting spacecraft of the impact points of jettisoned hardware, such as heat shields and parachutes, to a trajectory model the winds can be measured. We start our investigations with the Viking lander 1 mission and end with Schiaparelli. In-between we extract wind measurements based on observations of the Beagle 2, Spirit, Opportunity, Phoenix and Curiosity landing sites.

With one exception the wind at each site during the lander's descent were found to be $<8 \mathrm{~m} \mathrm{~s}^{-1}$. High speed winds were required to explain the displacement of jettisoned hardware at the Phoenix landing site. We found a tail wind $\left(>20 \mathrm{~m} \mathrm{~s}^{-1}\right)$, blowing from the north-west was required at a high altitude $(>2 \mathrm{~km})$ together with a gust close to the surface $(<500 \mathrm{~m}$ altitude) originating from the north. All in all our investigations yielded a total of ten unique wind measurements in the PBL. One each from the Viking landers and one each from Beagle 2, Spirit, Opportunity and Schiaparelli. Two wind measurements, one above about $1 \mathrm{~km}$ altitude and one below, were possible from observations of the Curiosity and Phoenix landing site.

Our findings are consistent with a turbulent PBL in the afternoon and calm PBL in the morning. When comparing our results to a GCM we found a good match in wind direction but not for wind speed. The information provided here makes available wind measurements previously unavailable to Mars atmosphere modellers and investigators.

Keywords: Mars, wind, trajectory, lander, PBL

\footnotetext{
* Corresponding author

** Phone: +358 504302984

Email address: mark.paton@fmi.fi (M. D. Paton )
} 
cloud features. Moores et al. (2016) modelled the trajectories of hardware jettisoned by Curiosity to verify their mesoscale modelling results.

\subsection{Wind-blown lander hardware}

The distribution of lander hardware on the surface such as heat shields and ${ }_{41}$ parachutes on the surface will be sensitive to the winds aloft in the Planetary 42 Boundary Layer (PBL), e.g. see Paton (2017). A way to determine wind speed, 


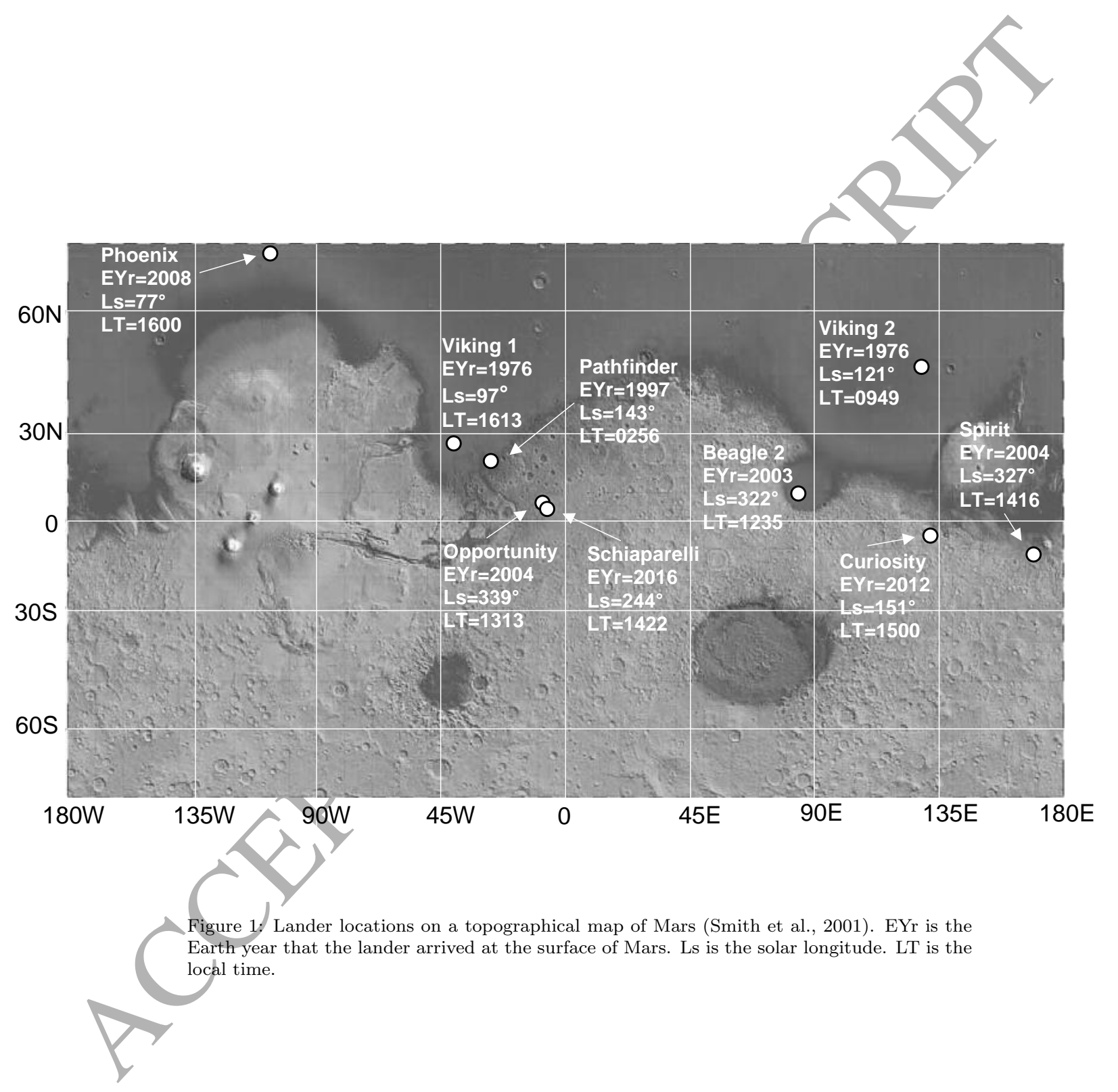


direction and limited information on the vertical structure on Mars is from trajectory modelling of jettisoned lander hardware Moores et al. (2016). As there have been a number of landings on Mars over a number of years and at a variety of locations, images of these sites could provide useful information on the variability of the Martian winds. Figure 1 shows the distribution of landers across Mars all of which, apart from VL-2 and Pathfinder, have landed in the afternoon when the atmosphere is most turbulent. In some cases strong turbulence (Seiff, 1993a) and gusts (Cheng et al., 2004) appear to have had a significant effect on the lander's motion during descent.

Mars Global Surveyor (MGS) and Mars Reconnaissance Orbiter (MRO) have imaged landers along with their jettisoned EDLS components on the surface of Mars. The images are all available via the HiRISE or MOC websites. The landers that have been imaged are Vikings 1 and 2, Pathfinder, the MER rovers Spirit and Opportunity, Phoenix and Curiosity. Attempts to image failed missions have been attempted. So far ESA's Beagle 2 (Merrifield, 2015) and Schiaparelli (see HiRISE website) have been spotted.

As can be seen in Table 1 the identification of jettisoned lander hardware are more certain when imaged up to a year or two after landing, i.e. from Spirit onwards in table 1. Older lander parts are presumably covered in Martian dust which makes spotting them difficult. For example the Viking lander 1 and 2 backshells have been observed but the parachutes have proved difficult to identify presumably because they are covered in dust. In some more recent cases EDL hardware has been imaged in situ by the lander. The HiRISE images of the Phoenix hardware, its heat shield and parachute are particularly clear and the certainty of their origin has been strengthened with images returned from the surface by the lander itself (image PIA11172).

Table 1: Lander hardware imaged on the surface of Mars. In the second column are listed the dates of Mars landings. The third column lists the image file names used for our analysis in this paper. Column four lists the dates when the lander site images were acquired. The fifth column, headed with 'Ca', lists the camera used. Hi stands for HiRISE aboard MRO and M stands for MOC aboard MGS. In the last three columns the headings of HS, P and B stand for Heat Shield, Parachute and Backshell respectively. In these column Y indicates a positive identification, $\mathrm{N}$ indicates no identification, $\mathrm{m}$ indicates possible identification of hardware. All the landers themselves were identified in all the images used.

\begin{tabular}{llllllll}
\hline Mission & Landed & Image ID & Acquired & Cam & HS & P & B \\
\hline VL-1 & $20 / 07 / 76$ & PSP_001521_2025 & $22 / 11 / 06$ & Hi & $\mathrm{m}$ & $\mathrm{m}$ & $\mathrm{Y}$ \\
VL-2 & $03 / 09 / 76$ & PSP_001501_2280 & $21 / 11 / 06$ & $\mathrm{Hi}$ & $\mathrm{m}$ & $\mathrm{N}$ & $\mathrm{Y}$ \\
Pathfinder & $04 / 07 / 97$ & PSP_001890_1995 & $21 / 12 / 06$ & $\mathrm{Hi}$ & $\mathrm{m}$ & $\mathrm{Y}$ & $\mathrm{Y}$ \\
Beagle 2 & $25 / 12 / 03$ & ESP_039308_1915 & $15 / 12 / 14$ & $\mathrm{Hi}$ & $\mathrm{Y}$ & $\mathrm{m}$ & $\mathrm{Y}$ \\
Spirit & $04 / 01 / 04$ & PIA05248 & $19 / 01 / 04$ & $\mathrm{M}$ & $\mathrm{Y}$ & $\mathrm{Y}$ & $\mathrm{Y}$ \\
Opportunity & $25 / 01 / 04$ & PIA05230 & $09 / 02 / 04$ & $\mathrm{M}$ & $\mathrm{Y}$ & $\mathrm{Y}$ & $\mathrm{Y}$ \\
Phoenix & $25 / 05 / 08$ & PSP_08591_2485 & $26 / 05 / 08$ & $\mathrm{Hi}$ & $\mathrm{Y}$ & $\mathrm{Y}$ & $\mathrm{Y}$ \\
Curiosity & $06 / 08 / 12$ & ESP_028401_1755 & $17 / 08 / 12$ & $\mathrm{Hi}$ & $\mathrm{Y}$ & $\mathrm{Y}$ & $\mathrm{Y}$ \\
Schiaparelli & $19 / 10 / 16$ & ESP_048041_1780 & $25 / 10 / 16$ & $\mathrm{Hi}$ & $\mathrm{Y}$ & $\mathrm{Y}$ & $\mathrm{Y}$ \\
\hline
\end{tabular}


107

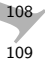

Figure 2 shows a generic EDL architecture representing a lander-type using powered descent. Similar lander architectures were used for the Viking landers, Phoenix and Curiosity. For Viking the parachute was deployed at around 5 $\mathrm{km}$ above the landing site (Cooley \& Lewis, 1977), $13 \mathrm{~km}$ altitude for Phoenix (Desai et al., 2011) and $12 \mathrm{~km}$ altitude for Curiosity (Cruz et al., 2014). The heat shield is jettisoned soon after the parachute is deployed, triggered by a timer. and then falls relatively quickly to the surface impacting the surface before the touchdown of the lander. The next relevant event for our analysis is when the lander separates from the backshell-parachute. This normally occurs around an altitude of $1 \mathrm{~km}$. After being released the lander performs a powered descent while the parachute and the connected backshell drift down to the surface. Other types of landing system have been used on Mars, i.e. Pathfinder, MER rovers. These differ in that they used a combination of solid propellant retrorockets and airbags for the final stage of the landing to bring the lander to rest. Beagle 2 was light enough that retrorockets were not required and airbags could be used to absorb the energy from the impact with the surface. See table A5 and A6 for lander EDLS properties and EDL trajectory parameters respectively.

Figure 3 compares the distribution of components from the landers imaged by HiRISE. The distances between the components were obtained from the HiRISE and MOC images. The direction of approach of the landers to the landing site has been normalised to an approach from the west. This then shows, that even with winds blowing, the heat shield always overshoots the landing site. The parachutes, being more sennsitive to the winds, are dispersed in a more random fashion.

\subsection{Mars atmosphere models}

Climate, mesoscale and microscale models are used independently and together to study the Martian atmosphere at different scales. As well as 3D models, 2D and 1D column models (Savijärvi, 1995, 1999; Savijärvi et al., 2004, 2005; Savijärvi \& Kauhanen, 2008; Savijärvi \& Määttänen, 2010) are used for studying the atmosphere of Mars.

General Circulation Models (GCMs) are tools used to understand and predict the state of the Martian climate. As they are global in scope GCMs generally are restricted, due to computing resources, to a cell size of the order of 100 $\mathrm{km}$ in size. In these cells the state of the atmosphere is calculated, i.e. pressure, temperature and winds. Processes that operate on smaller scale than the cell size, such as convection, are parameterised so their contribution can be included in the calculations making the results more accurate.

The Mars Climate Database (MCD) is a database (Millour et al., 2009; Millour et al., 2015) containing results from simulations run with the Laboratoire de Météorologie Dynamique (LMD) GCM. Included in the database are a number of scenarios that take into account two most variable forcings of the atmosphere which are due to UV input from the Sun and the amount and distribution of dust. The default "standard atmosphere" setting for the online web interface, which we used, contains results from a GCM run using dust distributions reconstructed from five Martian years of observations. The solar input for this 
(a)<smiles>C1C2CC1C2</smiles>

(b)

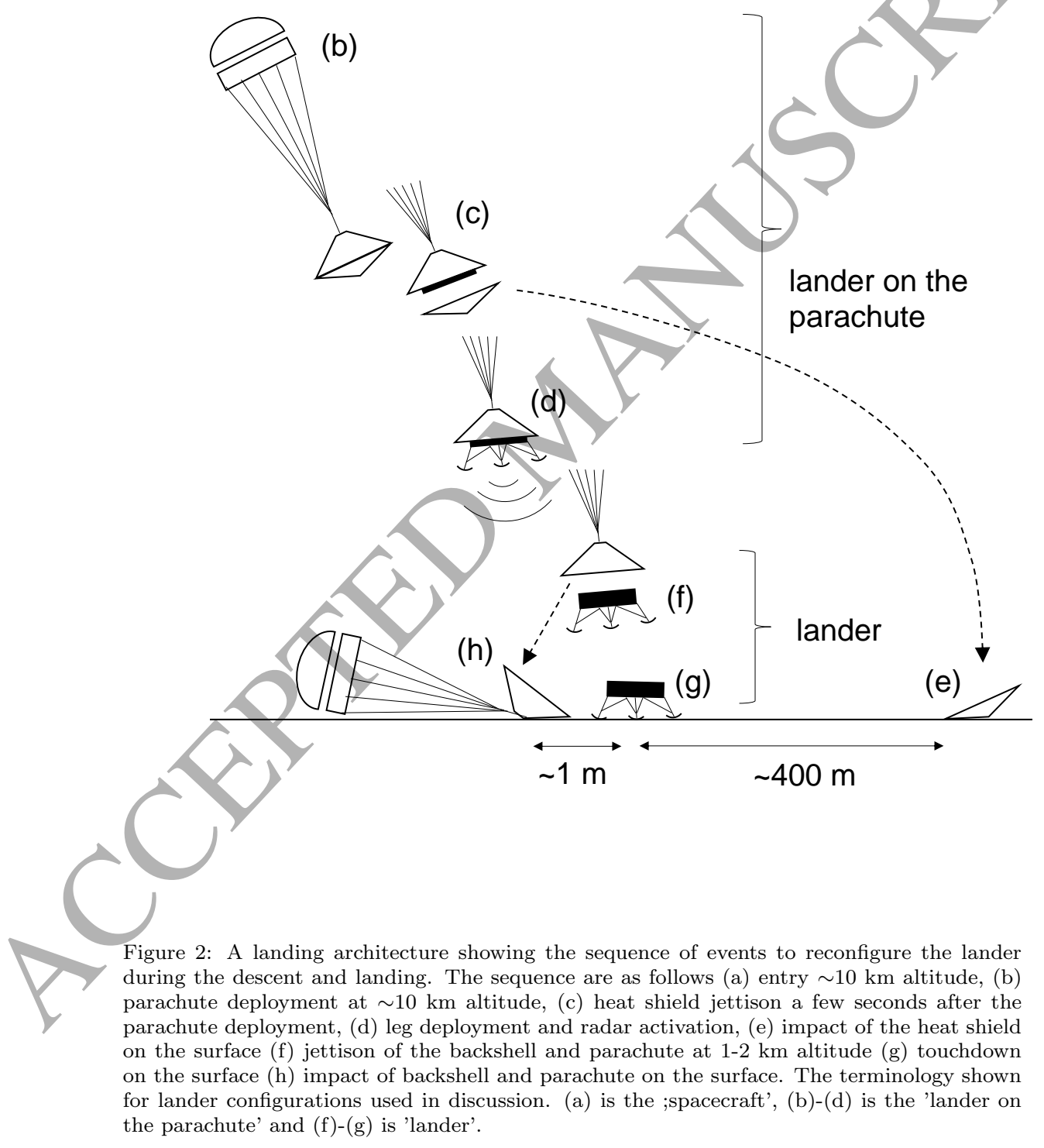

(c)

\section{spacecraft}

,

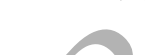


(a) MSL and its EDLS hardware

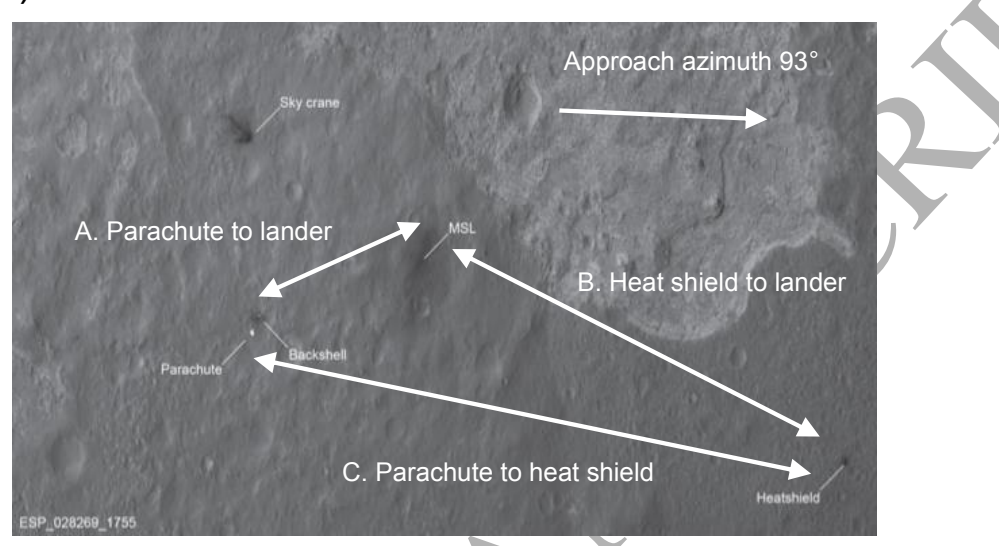

(b) Distribution of hardware from Mars landers

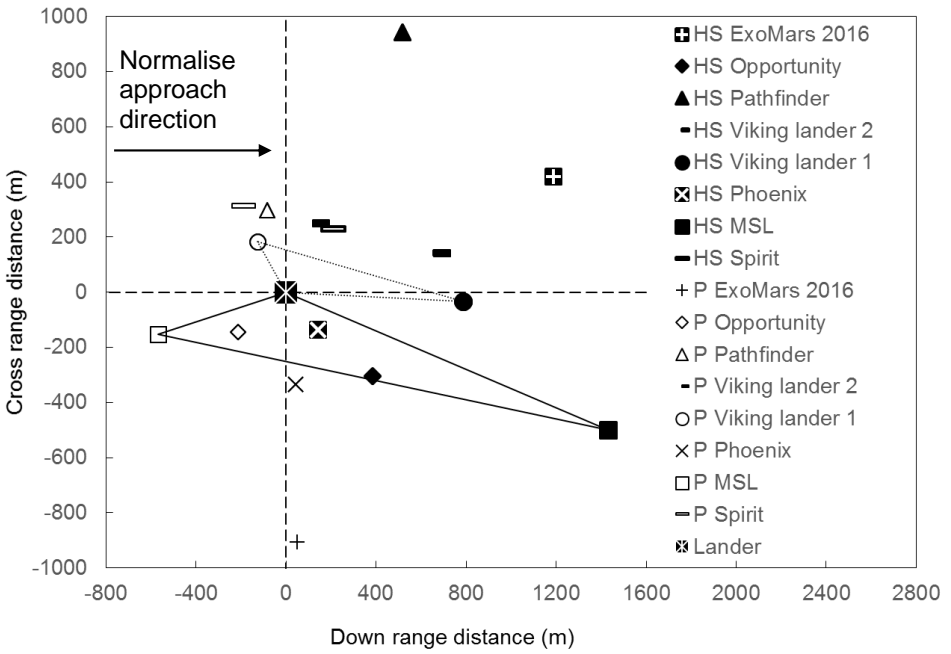

Figure 3: Locations on Mars of landed hardware from various missions. In (a) the EDL hardware at the landing site in Gale crater is shown. The distances used in section 3 The hardware for each mission is shown relative to the lander's touch down point. The dispersion of each mission's hardware on the surface is represented by the symbols in the legend. For VL-1 and Curiosity straight dotted and solid lines respectively are drawn between items of hardware to form triangles. 
setting is an average value. In our work we use this setting as a comparison with our derived values of wind as it represents an average climate. We also use other scenarios, or setting, and these include a cold atmosphere with a low amount of dust present and a warm atmosphere which is dusty.

\section{Method}

\subsection{Wind measurement procedure}

Two steps were required to obtain the wind measurements. First the distance between hardware components were obtained from the images. Then the trajectory model was run, varying the wind speeds and directions, until a match was found with the images.

The hardware component distances were calculated from JPEG2000 images (McEwen, 2007) available on the HiRISE website. The image viewing application HiView was used for this purpose. Table 2 lists the distance and orientation between the selected hardware components used to analyse the winds. These hardware components selected for analysis were based on those clearly identified in the images. Errors in measuring the distance between the hardware components was estimated to be at most one metre which translates to an uncertainty of about $2 \%$ when determining the wind speed.

Table 2: List of hardware components used for determining wind properties at the landing sites. For Beagle 2 'Pilot' and 'Ringsail' is shorthand for the pilot and ringsail parachutes respectively. For Spirit and Opportunity 'First bounce' refers to the first airbag impact on the surface. Uncertainty on the distance measurements are estimated to be of the order of one metre. The heading is an angle measured clockwise from the direction of the north pole. It is used to define the orientation of an object's path on the planet's surface, at any given point along its trajectory. The direction of travel is from the object's current surface location along the path defined by the heading. The heading is equivalent to azimuth as used in celestial mechanics. Note the meteorological convention for wind direction is in the opposite direction, i.e. the wind blows from the direction as defined by the azimuth angle.

\begin{tabular}{lllrr}
\hline Mission & From & To & Distance $(\mathrm{m})$ & Heading $\left(^{\circ}\right)$ \\
\hline Viking Lander 1 & Lander & Backshell & 245 & 282 \\
Viking Lander 2 & Lander & Backshell & 422 & 342 \\
Beagle 2 & Pilot & Ringsail & 106 & 323 \\
Spirit & First bounce & Heat shield & 373 & 72 \\
Opportunity & First bounce & Heat shield & 653 & 109 \\
Phoenix & Lander & Backshell & 331 & 173 \\
Phoenix & Lander & Heat shield & 195 & 45 \\
Curiosity & Lander & Heat shield & 1486 & 252 \\
Curiosity & Lander & Backshell & 569 & 115 \\
Schiaparelli & Backshell & Heat shield & 1773 & 40 \\
\hline
\end{tabular}

132 Once the separation distances had been measured a Hill Climbing algorithm 133 was used to control the fitting procedure. The algorithm automatically sampled ${ }_{134}$ a Gaussian probability distribution of the wind speeds, ran the trajectory model 
with these wind speeds and compared the results from the model with the impact locations observed in an image. A single or double wind layer was used by the trajectory model depending on the information available, i.e. number of hardware components available. One layer was used if either the lander and the parachute or the lander and the heat shield had been identified in the images. Double layers were possible if both the parachute and heat shield were identified together with the lander. Each layer normally had constant wind speed and direction. More elaborate functions could in principle be used to represent the winds in the model (see section 3.2).

The Hill Climbing algorithm worked as follows. The known hardware and trajectory properties, listed in tables A5 and A6, were used first to initialise the model. Estimates for the $u$ and $v$ wind speeds could be provided, if known, to initialise the model and speed up the search otherwise the wind speed was set to zero. After the model had been initialised with the initial wind speeds and run once a preliminary fit parameter value was calculated comparing the impact locations in the model to those in the image.

The Hill Climbing algorithm then generated new wind speed estimates by sampling probability distributions, one distribution for each $u$ and $v$ wind speed component, centred around the initial estimates of the wind speeds. The model was then run for a second time and a new fit parameter calculated. If the new fit parameter improved on the previous one the algorithm then switched to sampling probability distributions centred around the latest wind speed estimates. If there was no improvement then the algorithm kept sampling the previous probability distributions centred on the old wind speed estimates. The process was repeated until the fit parameter reached a predetermined value.

Figure 4 shows an example of convergence towards a wind measurement using the Monte Carlo based Hill Climbing algorithm. The wind profile in this case has $u$ and $v$ components both equal to $5 \mathrm{~m} \mathrm{~s}^{-1}$ above $1000 \mathrm{~m}$. Below this altitude the $u$ an $v$ components have values of $10 \mathrm{~m} \mathrm{~s}^{-1}$. A best fit parameter is used by the hill climbing algorithm to search for a wind speed and direction. The best fit parameter for a double wind layer, i.e. if the parachute and heat shield have been identified, is as follows.

$$
d_{b f}=\left(\left[x 1_{h \mathfrak{s}}-x 2_{h s}\right]^{2}+\left[y 1_{h s}-y 2_{h s}\right]^{2}\right)^{0.5}+\left(\left[x 1_{p c}-x 2_{p c}\right]^{2}+\left[y 1_{p c}-y 2_{p c}\right]^{2}\right)^{0.5}
$$

where, for the model output, $x 1_{h s}$ is the longitudinal distance between the lander and the heat shield, $y 1_{h s}$ is that latitudinal distance between the lander and the heat shield, $x 1_{p c}$ is the longitudinal distance between the lander and the parachute and $y 1_{p c}$ is the latitudinal distance between the lander and the parachute. The variables followed by a ' 2 ' denote that these distances are from the images of the landing sites. A single wind layer would require at least one jettisoned hardware item to have been identified in the image.

The Hill Climbing algorithm was normally halted when equation 1 was less than one. This provided more than enough precision when calculating the wind speed, i.e. $<0.01 \mathrm{~m} \mathrm{~s}^{-1}$ when tested against a reference wind profile with constant wind speed. 


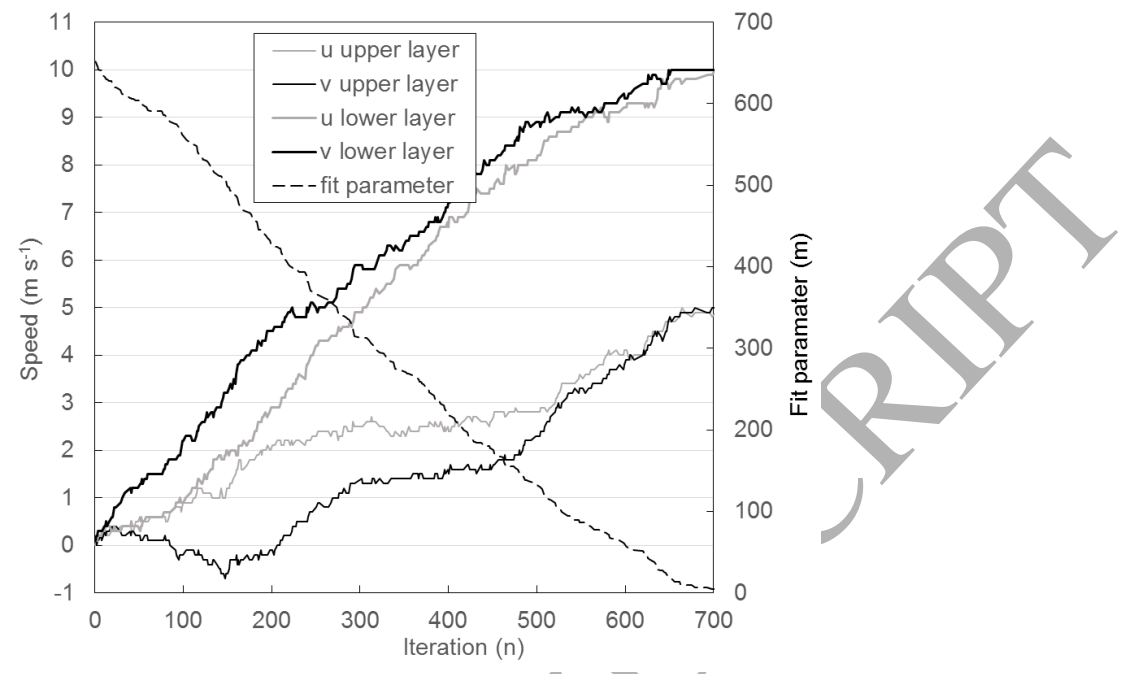

Figure 4: Progression of the fit, using a hill climbing algorithm, for a descending Phoenix-type lander that experiences winds.

Figure 5 shows an example of our approach applied to a notional reference Martian wind profile. This wind profile represents a typical wind profile on Mars that includes some variability with altitude. The wind blows from the west. Running the model with the reference wind profile produces a specific arrangement of impact points at the surface. These reference impact points can then used to determine the wind speed and direction for one wind layer, if just the heat shield is used, or two layers if the heat shield and parachute are used.

Notice how the single layer solution, in figure 5, is not some average of the winds acting on the heat shield above and below the parachute jettison altitude. For the single layer, with a wind speed of $10 \mathrm{~m} \mathrm{~s}^{-1}$ one may instinctively want to reduce the wind speed to obtain a fit. However this would not work because, above the parachute release altitude, a decrease in wind speed will increase the separation distance overall. See appendix section $\mathrm{C}$ for an example of this behaviour and its explanation.

In the model the winds are represented as $u$ and $v$ components as shown in figures 4 and 5 . The results in the paper are presented using the meteorology convention for wind speed and direction. For example the values in figure 4, for the upper layer, translate into a wind speed of $7 \mathrm{~m} \mathrm{~s}^{-1}$ with a wind originating from an azimuth of $225^{\circ}$, i.e. blowing from the south-west. Note the convention used for calculating the location of hardware relative to the lander and for the heading of the lander in flight is in the opposite sense, i.e. towards rather than from the azimuth. 


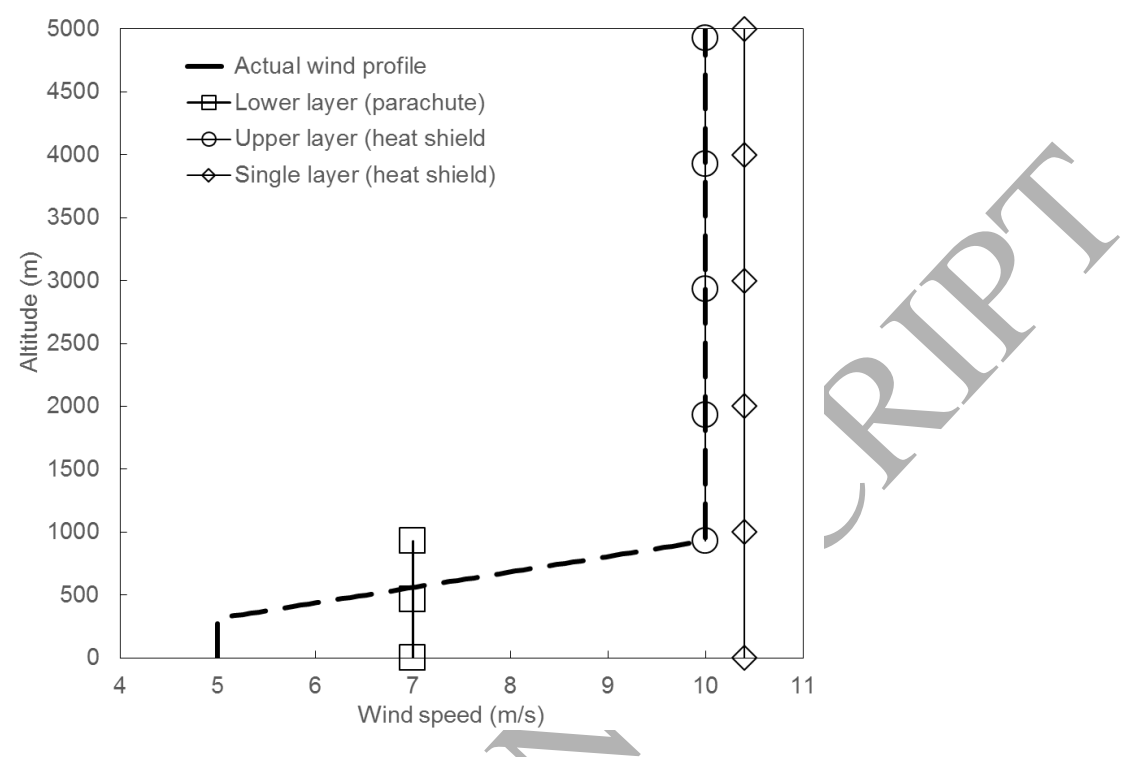

Figure 5: Wind layers as used in the results section fitted to a test profile. See the text for an explanation of the single and double wind layer solutions.

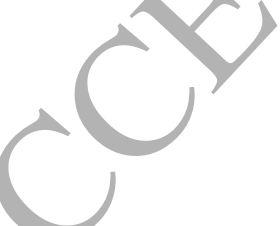

\subsection{Fitting realistic wind profiles}

In reality wind speed and direction, at any particular time on Mars, will likely vary with altitude (Petrosyan et al., 2011). An alternative approach to using wind layers with constant wind speed and direction is to vary these properties as some function of altitude in the model, e.g. using a polynomial or logarithmic function. This approach can then help with the interpretation with the results and identify possible trends.

As a minimum for an atmospheric layer of interest we use two linear functions connected at a mid-point to approximate a continuous profile and capture any swings in wind speed and direction. The formulation of the wind profile as a Piece-Wise Linear Function (PWLF) with two sections is as follows:

$$
\begin{gathered}
u=u_{\text {top }}+p_{f} \frac{1-\frac{z-z_{b o t}}{z_{t o p}-z_{b o t}}}{1-f_{\text {mid }}} \\
u=\frac{z-z_{b o t}}{z_{\text {top }}-z_{\text {bot }}} \frac{u_{t o p}-u_{b o t}+p_{f}}{f_{\text {mid }}}+u_{b o t}
\end{gathered}
$$

where $u_{t o p}$ is the wind velocity at the top of the layer, $p_{f}$ is a shape parameter, $z$ is the altitude, $z_{t o p}$ is the altitude of the upper boundary, $f_{\text {mid }}$ is the location of the point of the split in the layer and $u_{b o t}$ is the wind velocity at the bottom of the layer. If the mid-point is fixed then the only variable that is the shape parameter which makes it easy to incorporate into our Hill Climbing algorithm. 


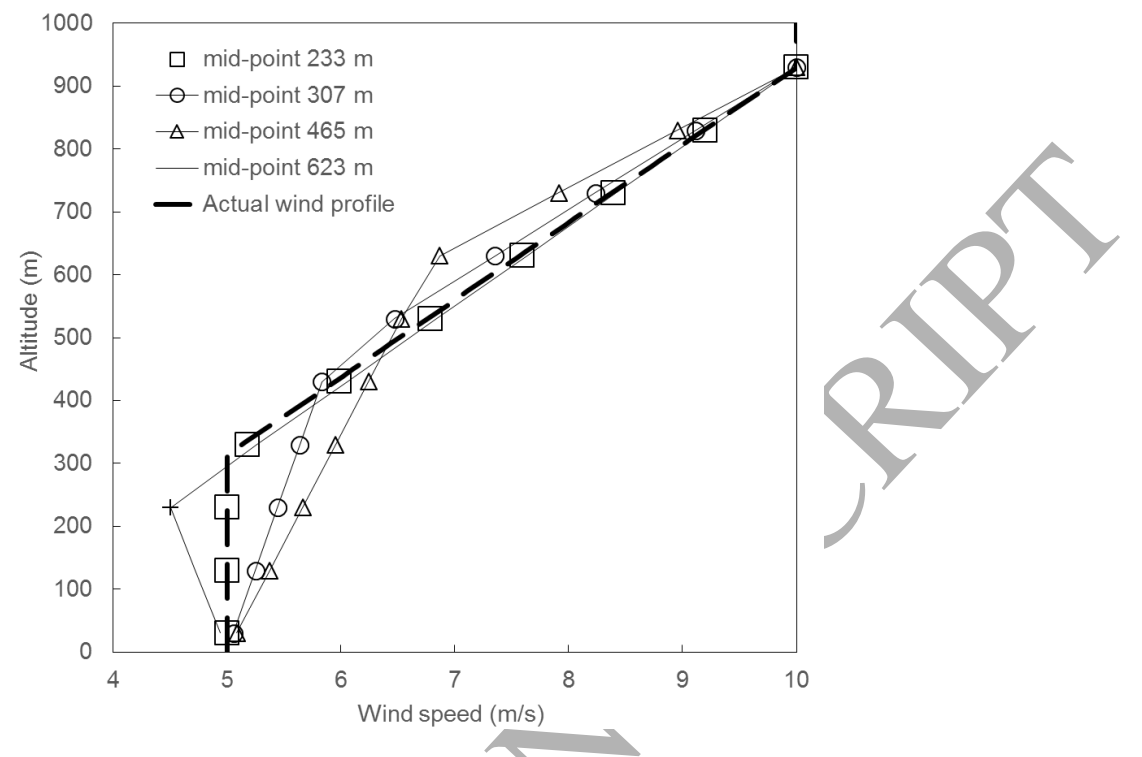

Figure 6: Reconstruction of the wind profile using a Piece-Wise Linear Function (PWLF). The point where each PWLF is connected is indicated in the legend.

Figure 6 shows the results of fitting a PWLF to a wind speed profile that varies in intensity with altitude. The mid-point for the fitted profiles are changed for each fitting attempt. As can be seen the algorithm can produce an exact solution for the wind profile if the mid-point is known. When using other points the profile is less accurate but the general trend can be discerned and aids interpretation when compared to GCM results or combined with previous wind measurements.

\subsection{Measurement uncertainty}

The vehicle's initial state, its aerodynamic properties during the descent and the jettisoned hardware aerodynamic properties are uncertain to one extent or another. If our trajectory model is run numerous times for a specific mission, each time with the same wind profile but sampling various probability distributions of the initial state values or vehicle properties, a probability distribution of landing locations are produced, i.e. a landing ellipse. In our case we initialise the trajectory models from the parachute deployment altitude not from entry as this would introduce unnecessary complexity in the modelling.

To shrink the landing ellipses to a single point, i.e. the impact location of jettisoned hardware observed in an image, a range of wind profiles are required. These wind profiles, calculated by the model, then represent our wind measurement. Note the landing ellipses or uncertainties, apart for Beagle 2, use more tightly constrained initial conditions and vehicle properties than calculated before entry as they use reconstructed values. See table A5 and A6 for trajectory 
and vehicle parameters used in the model and table A7 for input uncertainties.

Table 3 lists the $3 \sigma$ uncertainty on the separation distances between the heat shield and the lander for the Phoenix lander. See table A7 and the text in the appendix for the uncertainty on the model inputs for each mission. For the Phoenix case each model parameter was set their high and low values in turn, running the model with no winds, and noting the impact locations. As can be seen the uncertainty on the drag coefficient potentially accounts for more than half of the uncertainty (columns 3 and 4 in table 3 ) on the hardware locations.

Table 3: Sensitivity of hardware separation distance on initial conditions. Separation between the lander and heat shield without any uncertainty is $409 \mathrm{~m}$. The error estimates for the initial state of the lander on the parachute are based on the $1 \sigma$ values listed in the dataset of properties derived from IMU measurements (PHX-M-ASE-5-EDL-RDR-V1.0). The uncertainty on the drag coefficient is typical for parachutes deployed for Mars, e.g. see Cruz et al. (2003).

\begin{tabular}{lrr}
\hline $\begin{array}{l}\text { Model } \\
\text { input }\end{array}$ & $\begin{array}{l}\text { Input } \\
\text { uncertainty }\end{array}$ & $\begin{array}{r}\text { Heat shield displacement } \\
\text { uncertainty }(\mathrm{m})\end{array}$ \\
\hline$\alpha\left({ }^{\circ}\right)$ & +1 & +9 \\
\hline$v\left(\mathrm{~m} \mathrm{~s}^{-1}\right)$ & +12 & -9 \\
\hline$z(\mathrm{~m})$ & -12 & +1 \\
\hline$\left.\rho(\mathrm{kg} \mathrm{m})^{-3}\right)$ & +700 & +2 \\
\hline$C_{D p}$ & -700 & -2 \\
\hline$C_{D h s}$ & $+5 \%$ & -8 \\
\hline \hline
\end{tabular}

The uncertainties on wind speed and direction are shown in figure 7 for the Phoenix case for a single wind layer from the surface to the parachute deployment altitude. These values were calculated as follows. A reference case was run with wind speed and direction set to some non-zero amount and the vehicle properties all set to their nominal values. This generated a set of reference impact points. Next the vehicle's properties were set to their high and low $3 \sigma$ values in turn and the search algorithm run to find the corresponding uncertainties on the winds speeds.

Figure 7 shows the dependence of the wind speed and direction uncertainties on wind speed for various model input uncertainties. Figure 7 (a) and (b) shows the wind uncertainties due to the uncertainty on the heat shield drag coefficient. In figure 7 (a) the wind speed uncertainty decreases with increasing speed. In figure 7 (b)The wind direction uncertainty totals $180^{\circ}$ at a wind speed of $0 \mathrm{~m}$ $\mathrm{s}^{-1}$. The directional uncertainty reduces to only a few degrees at $30 \mathrm{~m} \mathrm{~s}^{-1}$. The large directional uncertainty at low wind speed is related to the displacement of a heat shield if its drag coefficient is changed. This displacement can be larger than the distance displaced by low speed winds. See Appendix D for a detailed discussion on how uncertainty in heat shield drag coefficient can 
produce contradictory direction information.

Figure 7 (c) shows the uncertainty on wind speed due to other model input uncertainties. The uncertainties on initial altitude, velocity and flight path angle do not produce any uncertainty on wind direction so a figure demonstrating this is not shown. Figure 7 (d) shows the uncertainty on the wind speed determined from the jettisoned parachute due to uncertainty on its drag coefficient. The uncertainty on the initial conditions, parachute deployment condition, do not in general affect the displacement of the jettisoned parachute relative to the lander. By the time the parachute is jettisoned the lander has reached equilibrium with the atmosphere, i.e. it is descending vertically relative to the winds.

\section{Low altitude $(<12 \mathrm{~km})$ winds}

The wind profiles in this section consist of single layer constant value wind profiles for Viking lander 1 and 2, Beagle 2, Spirit and Opportunity. Double layer wind profiles, each layer with constant values, are included in this section for Phoenix and Curiosity. The wind profiles are derived from the technique described in subsections 3.1. and 3.2 Table A.5 and A.6 in the appendix contain information on the lander properties and details of the EDL events

\subsection{Viking landers}

The Viking Landers descended through the Martian atmosphere using an aeroshell fitted with a heat shield to protect the landers from the extreme thermal environment during the initial high speed entry. The aeroshell then slowed the lander down to a speed of just above Mach 1 (Cooley \& Lewis, 1977) at an altitude of about $5.9 \mathrm{~km}$ above the landing site allowing a parachute to be deployed. A timer was used to trigger the release of the heat shield at an altitude of $4 \mathrm{~km}$ seven seconds after parachute deployment. At $1.5 \mathrm{~km}$ above the surface the backshell while still connected to the parachute, was jettisoned and the lander performed a powered descent to the surface using its rocket engines.

Only the location of the backshell relative to the lander was used for the analysis. The heat shield in the published HiRISE image has not been positively identified. For comparison, data from the MCD for different climate scenarios and the near-surface winds measured by the Viking landers over subsequent sols after the landing (Hess et al., 1977).

Seiff (1993a) have determined the winds between 5.5 and $1.5 \mathrm{~km}$ altitude for the Viking landers while they descended on the parachute. These winds are presented and discussed in section 5 together with our results.

For VL-1 the application of our method described in subsections 3.1 and 3.2 yields a wind originating from south-east as shown in figure 7 (a) and a wind speed of about $3 \mathrm{~m} \mathrm{~s}^{-1}$ as shown in figure 7 (b). For VL-2 a wind blowing from the south and at a speed of about $3 \mathrm{~m} \mathrm{~s}^{-1}$ is determined using our method. The wind profiles determined from EDLS trajectory modelling appears to be in general agreement with the MCD wind profiles for a low dust and minimum solar activity climate scenario. They do not agree very well with wind measurements made by Seiff (1993a) an issue which is explored further in section 5 . 
(a) Heat shield drag coefficient

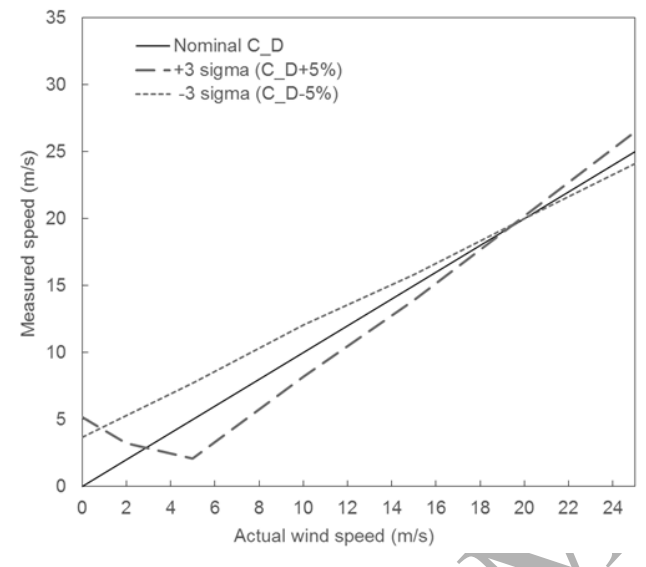

(c) Heat shield altitude, velocity and FP angle

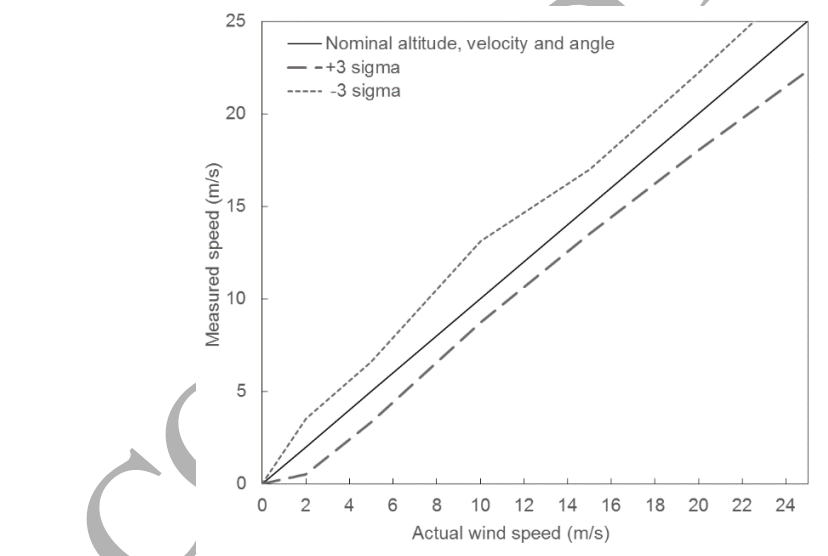

(b) Heat shield drag coefficient

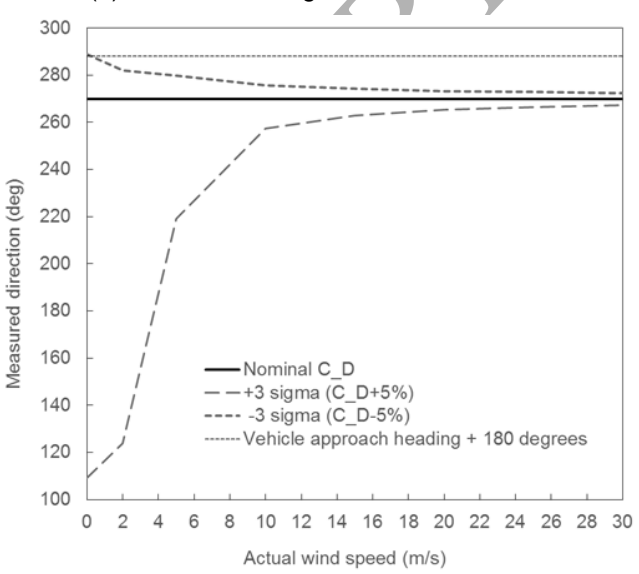

(d) Parachute drag coefficient $(<1 \mathrm{~km}$ altitude)

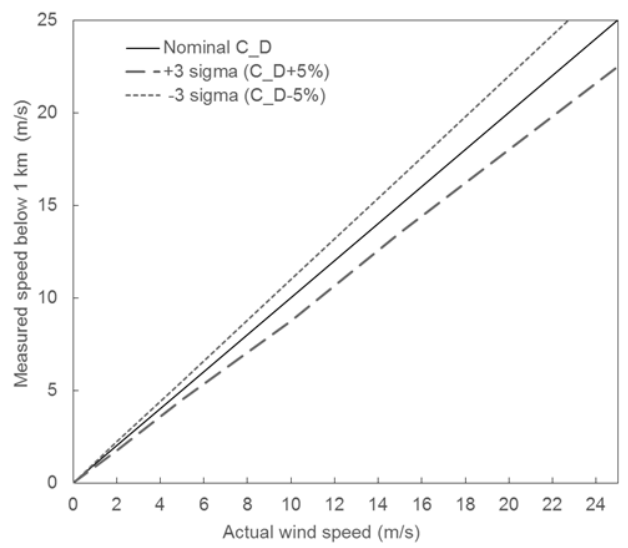

Figure 7: The uncertainty on the wind speed and direction measurements. 


\subsection{Pathfinder, Beagle 2, Spirit and Opportunity}

During the final stage of landing Pathfinder (Spencer et al., 1999), Beagle 2 (Taylor, 2000), Spirit and Opportunity landers (Cheng et al., 2004) used landing bags to bounce across the surface and absorb the impact velocity. For Spirit and Opportunity images of the landing sites show the first impact of the air bags shortly after the parachute had been jettisoned. Therefore it is straightforward to determine the wind speed and direction from this impact point and the heat shield impact point. For Pathfinder images of the landing site do not seem to show the impact point of its airbags. A wind profile is therefore not provided for Pathfinder. For Beagle 2, which did not use Rocket Assisted Descent (RAD), the ring sail parachute (Fallon \& Sinclair, 2003) would presumably impact the surface close to where the airbags impacted the surface. This would make the ring sail parachute imaged in the HiRISE image suitable for analysis together with the backshell also in the image. A full list summarising the hardware components and images used can be found in tables 1 and 2 .

The wind speed and direction during the Beagle 2 landing was determined to be $4 \mathrm{~m} \mathrm{~s}^{-1}$ blowing from the north-west. This result is representative of the wind speed below $7.1 \mathrm{~km}$ after the first parachute had been deployed. The first parachute was a relatively large pilot parachute aiding the deployment of the main ringsail parachute by slowing the lander down from supersonic to subsonic speed. See tables A.5 and A.6 for further details regarding Beagle 2's two-stage parachute system.

For Spirit it was found that the it experienced a wind speed of $5 \mathrm{~m} \mathrm{~s}^{-1}$ blowing from the west. For Opportunity, see figures 8 (e) and (f), the wind speed was $8 \mathrm{~m} \mathrm{~s}^{-1}$ blowing approximately from the south.

\subsection{Phoenix}

The Phoenix lander used a similar EDLS to the Viking landers including an aeroshell, parachute and powered descend for a soft touch down on the surface (NASA, 2008; Witkowski et al., 2009; Szalai et al., 2011). The altitude of parachute deployment for Phoenix was over twice the altitude of the Viking landers (see table A.5). The jettisoning of the parachute and backshell, on the other hand, was significantly lower at $930 \mathrm{~m}$ rather than $1.5 \mathrm{~km}$ for the Viking landers. The hardware components from the Phoenix landing, i.e. the heat shield, parachute and lander itself, are very clearly distinguished in the HiRISE images. The heat shield was also imaged from the lander when on the surface. With the heat shield and parachute available for the analysis it is possible to obtain some information regarding the structure of the wind profile.

In the trajectory model the atmosphere of interest was divided into two layers, with differing wind properties for each layer. The upper layer started at the parachute deployment altitude of $13.3 \mathrm{~km}$ and ended at the parachute jettison altitude of $930 \mathrm{~m}$. The lower layer started at the parachute jettison altitude and ended at the surface. The boundary between the layers was placed at the parachute jettison altitude because the separation distance between the parachute and lander is sensitive to winds below this altitude. 


\subsection{Key results collected together}

Table 4 presents our wind measurements as a table together with the latitude, longitude, local time and solar longitude at the time of landing. Single wind layers with constant wind direction and speed were used for all landers except Phoenix and Curiosity where two wind layers, each with constant wind and speed were used.

Figure 8 shows the wind direction and speed for those winds aloft in the PBL as determined from trajectory modelling of the EDLS hardware compared 
Table 4: Wind direction and speed. ADD MORE INFO.

\begin{tabular}{lrrrrrrr}
\hline Mission & $\begin{array}{r}\text { alt. } \\
(\mathrm{km})\end{array}$ & $\begin{array}{r}\text { dir. } \\
\left({ }^{\circ}\right)\end{array}$ & $\begin{array}{r}\text { speed } \\
\left(\mathrm{m} \mathrm{s}^{-1}\right)\end{array}$ & $\begin{array}{r}\text { lat. } \\
\left(^{\circ}\right)\end{array}$ & $\begin{array}{r}\text { long. } \\
\left(^{\circ}\right)\end{array}$ & $\begin{array}{r}\text { Ls } \\
\left({ }^{\circ}\right)\end{array}$ \\
\hline Viking lander 1 & $0-1$ & 129 & 3.0 & 22.5 & 312 & 1618 & 97 \\
Viking lander 2 & $0-1$ & 161 & 2.2 & 48 & 134 & 0949 & 121 \\
Beagle 2 & $0-7$ & 300 & 3.9 & 11.5 & 90 & 1235 & 322 \\
Spirit & $0-7$ & 265 & 4.9 & -14.6 & 175 & 1416 & 327 \\
Opportunity & $0-7$ & 184 & 8.2 & -2 & 354 & 1313 & 339 \\
Phoenix & $0-1$ & 360 & 9.9 & 62 & 234 & 1600 & 77 \\
Phoenix & $1-12$ & 316 & 21.2 & 62 & 234 & 1600 & 77 \\
Curiosity & $0-2$ & 117 & 5.1 & -5 & 137 & 1500 & 151 \\
Curiosity & $2-12$ & 167 & 4.3 & -5 & 137 & 1500 & 151 \\
Schiaparelli & $0-7$ & 11 & 5.0 & -2 & 354 & 1422 & 244 \\
\hline
\end{tabular}

$$
412
$$

to the "standard atmosphere" obtained from the MCD. Some details regarding the MCD and its settings can be found in subsection 2.2 .

In figure 8 it can be seen that the wind speed does not appear to agree very well with the $\operatorname{MCD}\left(R^{2}=0.34\right)$ while the wind direction agrees quite well $\left(R^{2}=0.86\right)$. The EDLS derived wind speeds in figure 8 (a) appear to be weakly correlated with the MCD results. This could be at least partly due to the large uncertainty on knowing the aerodynamic properties of the jettisoned EDLS components. For about half of the cases the MCD appears to be in clear disagreement with the EDLS derived wind speeds and their associated uncertainties. The most notable is the wind speed for Phoenix between an altitude of 1 and $12 \mathrm{~km}$.

In figure 8 (b) the wind direction provided from the MCD appear to be in better agreement with the EDLS derived wind direction. Phoenix, represented by the circle and diamond near the top of the chart, has clearly different wind speeds to the MCD.

\section{Winds in the PBL}

In this section we discuss selected missions, i.e. VL-1, VL-2 and Phoenix, that allow us to probe the winds in the Martian PBL. The displacement of the Viking lander parachutes allowed us to measure the wind speed and direction below an altitude of $1.5 \mathrm{~km}$. Coupled together with previously published wind profiles from 5.5 to $1.5 \mathrm{~km}$ this allows us to probe the wind conditions at these sights in some detail. For Phoenix the wind speeds are high compared to average PBL wind speeds suggesting some atmospheric disturbance .

\subsection{The Viking landers}

Wind profiles have been determined (Seiff, 1993a) from measurements made by the Viking landers as they descended by parachute (see figure 9) from an 
(a)

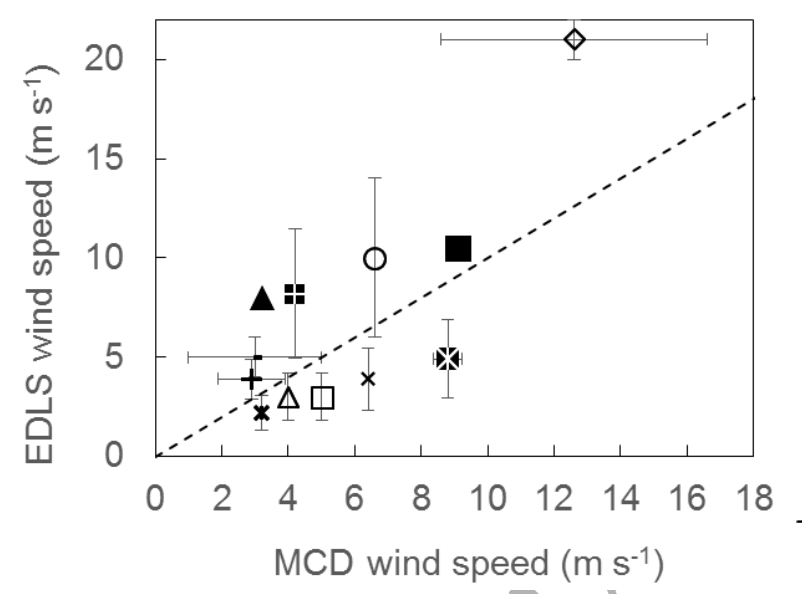

$\square \quad$ VL-1 0-1.5 km

* VL-2 0-1.5 km

$\times$ Beagle 2 0-7 km

* Spirit 0-7 km

- 1.5 km (DIMES)

- Opportunity

• $1.5 \mathrm{~km}$ (DIMES)

O Phoenix 0-1 km

$\diamond$ Phoenix 1-12 km

+ Curiosity 0-1.6 km

$\Delta$ Curiosity 1.6-12 km

- Schiaparelli 0-11 km

(b)

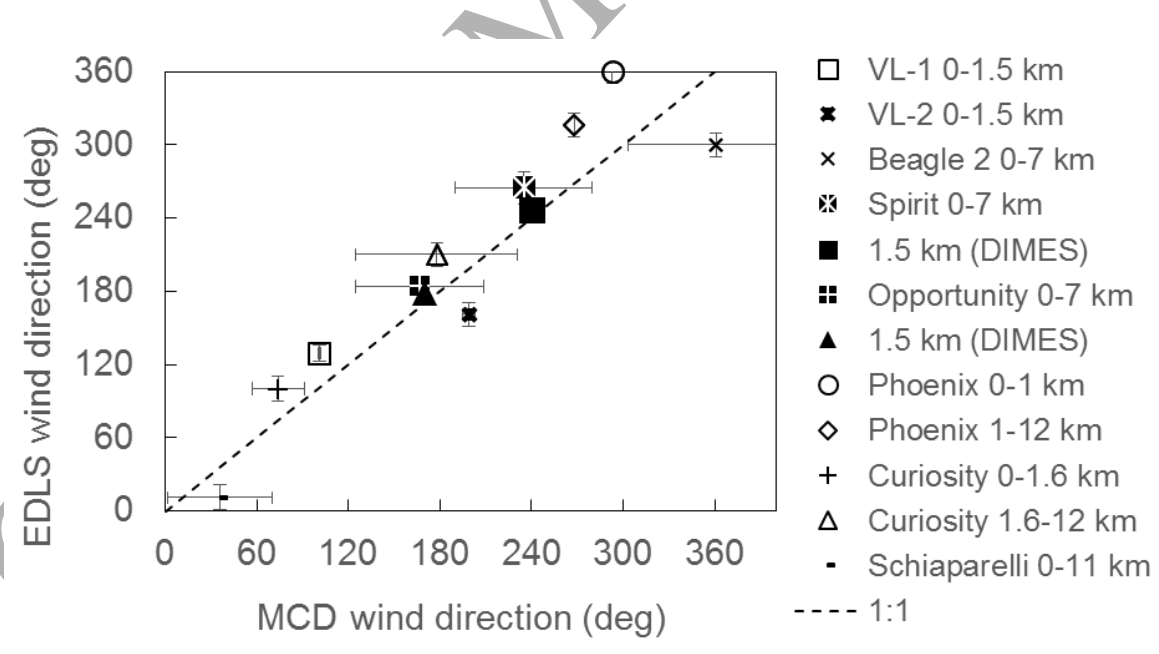

Figure 8: Wind speed and direction from EDLS and MCD compared. Vertical error bars take into account the uncertainty on the aerodynamic properties. The horizontal error bars represents the range of wind properties over the descent. 


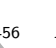

457 Ten PWLF parameters were varied in the model to achieve a fit. These 5. parameters were varied by the Hill Climbing algorithm described in section 3.1.

altitude of 5.5 to $1,5 \mathrm{~km}$. We used two PWLFs in our model, one for the $u$ wind speed component and another for the $v$ wind component, to represent the winds below $1.5 \mathrm{~km}$ altitude. A Hill Climbing algorithm (see section 2.2) was used to vary the PWLF shape parameters until a fit between the model and observed location of the parachute was found. The PWLFs were bounded by wind measurements at $1.5 \mathrm{~km}$ altitude and at the surface (Seiff, 1993a). The altitude of the PWLF mid-point was set manually to three different heights to provide three pairs of $u$ and $v$ PWLFs. These are converted into wind speed and direction in figure 9.

For VL-1 Seiff (1993a) suggested that high wind speeds during the parachute descent, see figure 9 (b), was likely caused by cold air advection from the southeast. Figures 9 (a) and (b) possibly support this interpretation, i.e. southeasterly wind. However in figure 9 (a) the wind swings around so it is blowing from the north quite soon after the jettison of the parachute. This is different from the MCD and perhaps suggests a more local disturbance in the atmosphere below an altitude of $1.5 \mathrm{~km}$.

Seiff (1993a); Haberle et al. (1993) suggested local topography modified the large-scale slope wind as revealed by the winds measured for VL-2, e.g. see wind profile above $1.5 \mathrm{~km}$ altitude in figures 9 (c) and (d). Fitting a PWLF to the Viking data does not seem to support or refute this interpretation from Seiff (1993a); Haberle et al. (1993) but what is interesting is the structure in the wind profile in figure 9 (c) seems to support the prediction that the boundary layer at the VL-2 site was only $500 \mathrm{~m}$ in height at the landing time of 0949 LT. There is a small rotation from about $130 \%$ to $180^{\circ}$ in the wind direction below this altitude.

\subsection{The Phoenix case}

Out of all the wind measurements, in section 4, Phoenix had the largest difference in wind speed when compared to the MCD. To investigate nonmodelling, i.e. physical, causes of the mis-match we added realistic PWLF wind profiles to our trajectory model. See section 3.2 for more information on using PWLF wind profiles.

The PWLFs were arranged as follows. Two PWLFs, one for each $u$ and $v$ component of wind speed, were used in the top wind layer and two similar PWLFs were used in the bottom layer. The upper point of the PWLF representing the $u$ component of wind speed in the bottom layer was set equal to the lower point of the $u$ component PWLF in the top layer. The $v$ component PWLFs in the top and bottom layers were also vertically connected in this way. Altogether the trajectory model used four PWLFs.

Each parameter was sampled from ten independent Gaussian distributions. Four of the parameters were two $u$ and $v$ wind speed pairs, one pair for the upper points of two top layer PLWFs, and the other pair for the lower points of the two bottom layer PLWFs. An additional two parameters, a $u$ and $v$ pair, were used to vertically connect the PWLFs. The remaining four parameters were for 
(a) VL-1 wind direction

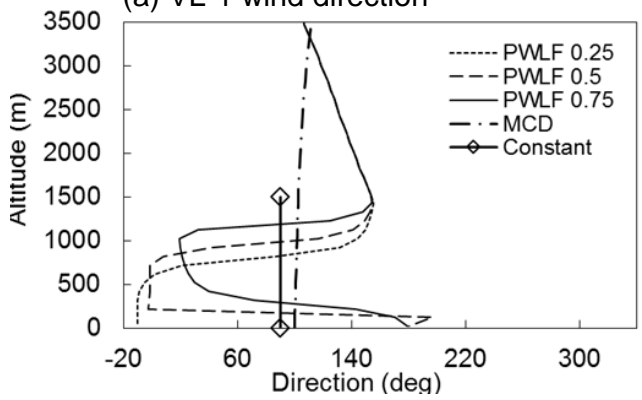

(c) VL-2 wind direction

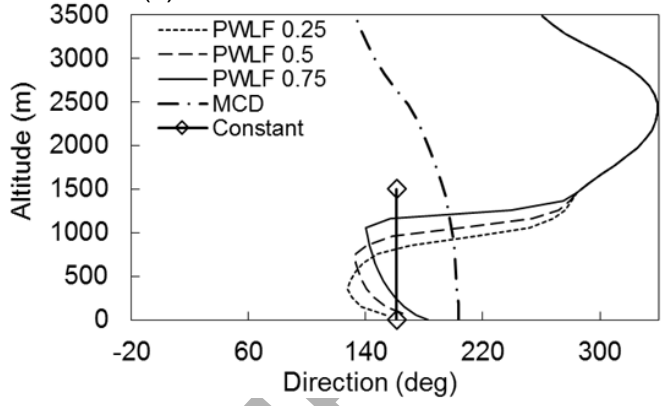

(b) VL-1 wind speed

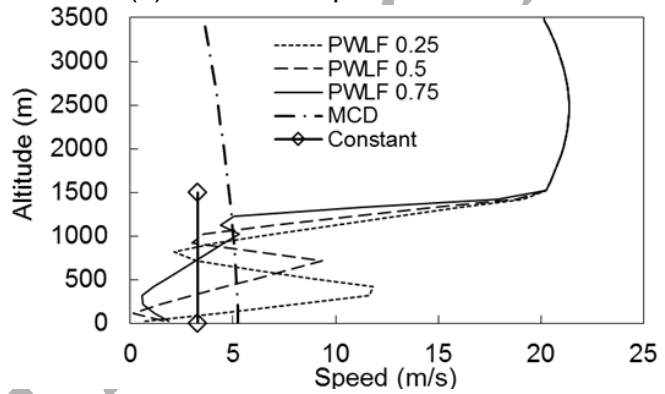

(d) VL-2 wind speed

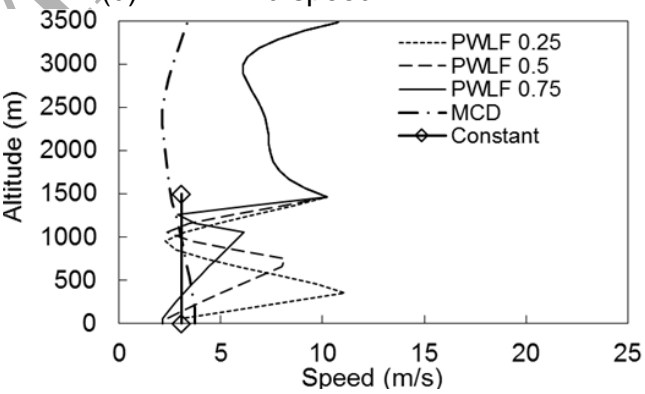

Figure 9: Wind speed and direction from EDLS and MCD compared for the Viking landers. A piece-wise linear function described in section 3 is used to help highlight any possible structural detail. The numbers $0.25,0.5$ and 0.75 in the legend refer to a scaling factors used to vary the mid-point of the PWLF relative to the lower boundary, i.e. $1.5 \mathrm{~km}$, of the wind profiles provided by Seiff (1993a) and presented in this figure as the constant curves. 
controlling the shape of the four PLWFs. The altitudes of the points connecting the upper and lower PLWFs could also be varied but were set manually. Their values can be found in the caption for figure 10 presented as a fraction of the parachute deployment altitude.

The results in figure 10 for PWLF A are in general agreement with the results in section 4 . In figure 10 it can be seen that the wind speed rapidly decreases to a minimum at about $2 \mathrm{~km}$ above the surface. The wind direction then abruptly swings round from a north-westerly to a north-easterly and the wind speed rapidly increases towards the surface. Figure 11 shows our trajectory simulations for wind blown lander and the jettisoned hardware components superimposed on an image of the Phoenix landing site. It can be seen the heat shield was only mildly deflected from the incoming path of Phoenix while the parachute had been strongly deflected. It should be noted that while the heat shield was not deflected to the south it did experience a strong tail wind, together with the lander on the parachute, which reduced its separation from the lander. See appendix D for an explanation of this behaviour as it may not immediately obvious how a tail wind could reduce the separation distance between the heat shield and the lander.

The wind speed and direction profiles from the three MCD climate scenarios are included in figure 10 for reference. It can be seen that none of the scenarios can produce the high wind speeds especially at higher altitude. The upper altitude wind speeds we measured are similar to measurements made by Karatekin \& Asmar (2011) who estimated a wind speed of $30 \mathrm{~m} \mathrm{~s}^{-1}$ during the parachute descent. These Doppler measurements were made along the line of site between Earth and Phoenix, which approximately lined up with the approach heading of the lander to its landing site, i.e. from the north-west to the south-east. Lift forces, which we neglected in our model, caused by a possibly deformed heat shield (Desai et al., 2011) are not thought to have a significant contribution. The heat shield was most likely spinning during the descent (Desai et al., 2011) cancelling out any lift forces.

A magnified image of the Phoenix parachute is shown in figure 12. A strong northerly wind near or at the surface, as suggested in our modelling results, is apparent. The roundness of parachute canopy of the Phoenix lander in figure 12 (d) suggests the canopy was inflated by an intense horizontal wind as it came to rest on the surface. The orientation of the parachute relative to the backshell, to which it is attached, is consistent with a wind blowing from the north. In contrast to the round canopy of Phoenix images of the parachute canopies for Spirit, Opportunity and Curiosity in figures 12 (a) to (c) suggests their canopies collapsed before reaching the surface. This would indicate the winds at these sites were not so strong at landing.

The shape of the Curiosity parachute canopy was observed to change sporadically due to strong surface winds (https://www.uahirise.org/releases/mslchute.php). The first change was observed in an image acquired 3.5 months after the landing. Previous images were acquired after 12 days and about one month after landing showing no change in canopy shape. Images of the Phoenix canopy were acquired 11 hours, 22 hours and 55 sols (see MRO image PSP_009290_2485) 
(a)

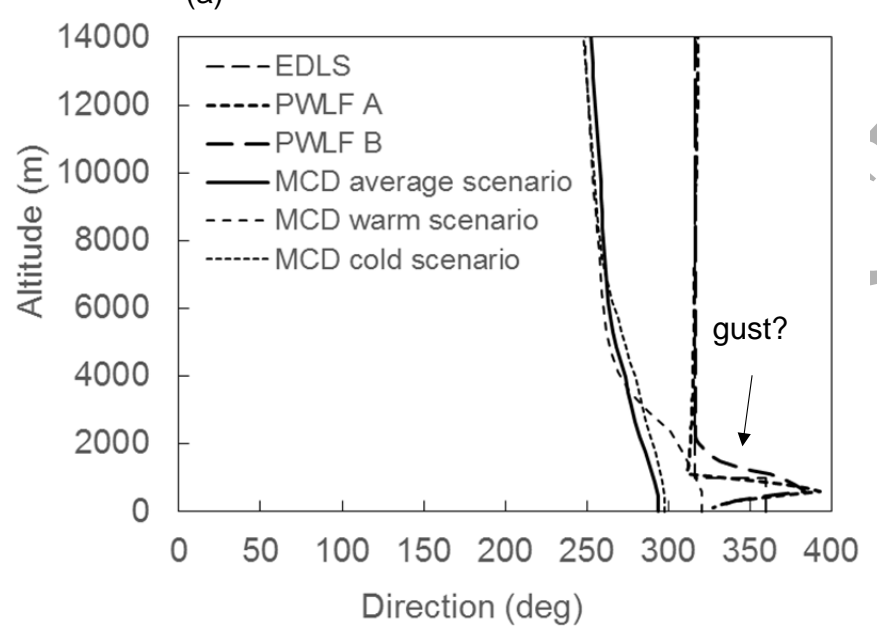

(b)

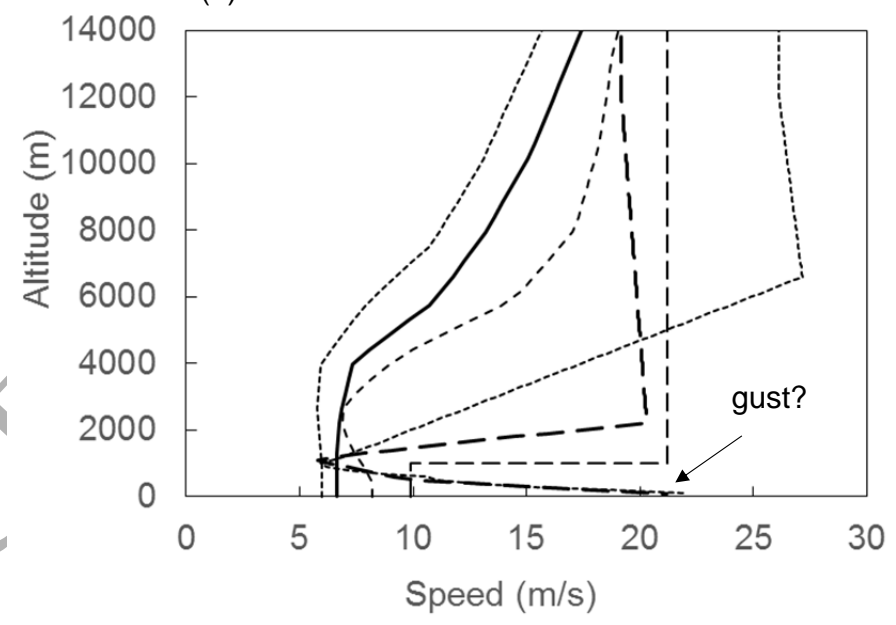

Figure 10: Wind speed and direction derived from the scatter of EDLS hardware on the surface compared to MCD standard atmosphere for Phoenix landing site. A PWLF (section 3.3) was used with four sections. The locations of these fixed points were at 13, 2, 1, $0.5 \mathrm{~km}$ for PWLF A and at 13, 6, 1, $0.5 \mathrm{~km}$ for PWLF B. 
after landing showing no change in canopy shape. It appears unlikely that a surface gust could have altered the shape of the parachute canopy in the first 11 hours of landing although it is not beyond the realms of possibility.

Wind gusts near the surface of Mars could be quite common and may present an unseen risk to landing spacecraft. Dust devils at least appear to quite common on Mars (Spiga et al., 2016; Chapman et al., 2017; Lorenz \& Jackson, 2016) A dust devil or large turbulent eddy may be responsible for the high wind speed near the surface in figure 10 (b). The Phoenix landed in afternoon when the atmosphere is at its most turbulent. At least one lander, Spirit, has experienced a Martian gusts during landing (Cheng et al., 2004).

For Phoenix the probability of encountering a convective vortex during landing can be easily calculated. Ellehoj et al. (2010) identified 502 pressure drops in the Phoenix pressure data that were associated with convective vortices passing over the lander. Ellehoj et al. (2010) determined that during the first sols of the mission the frequency of passing convective vortices in the afternoon was around 0.2 per hour. This would translate to a 1 in 300 chance Phoenix would have encountered a convective vortex during the final minute of its descent as it descended in the afternoon.

Characterisation of the winds aloft in the PBL properly, in terms of its gustiness, with the appropriate instruments and modelling would probably be a prudent exercise given the apparent variations in the intensity of the Martian winds. Such measurements would benefit future Mars landings and the protection of prelanded assets from wind blown components jettisoned during the descent (Paton, 2017).

\section{Conclusions}

We have determined in situ for the first time the wind properties aloft in the PBL at a variety of landing sites over the surface of Mars. The resulting wind information spans a period of four decades or 21 Mars years. We used a trajectory model to analyse the orbital images of jettisoned hardware and determined the wind speed and direction that could account for their distribution on the surface. In addition to orbital images of successful landed missions we were able to extract useful information from images of Beagle 2 and Schiaparelli hardware on the surface. To interpret our results comparisons were made to the atmospheric winds from the state of the art Mars Climate Database (MCD).

We found the wind speed in the Martian PBL to be $<8 \mathrm{~m} \mathrm{~s}^{-1}$. One exception was Phoenix landing site where wind speeds $>20 \mathrm{~m} \mathrm{~s}^{-1}$ were required to explain the displacement of the heat shield and a wind gust close to the surface was required to explain the displacement of the parachute. Further analysis suggests the wind speed dropped below the tolerance of the EDLS just long enough for Phoenix to be successfully released from the parachute.

Our results suggest that the wind direction on Mars generally correlates over a period of at least 21 Martian years, i.e. over the period of landings on Mars, with the MCD. On the other hand the wind speeds are not in such good 


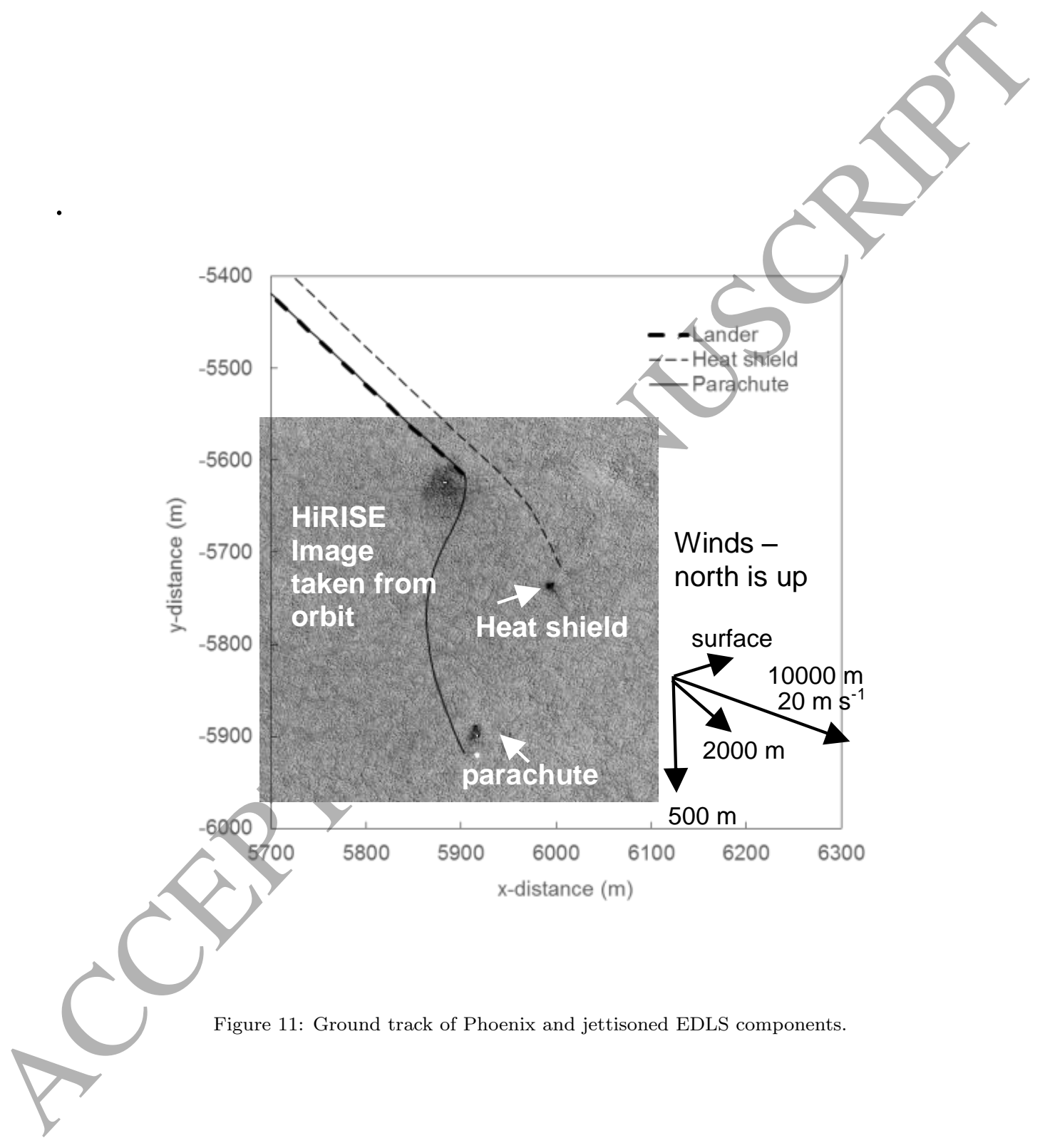


(a) Spirit

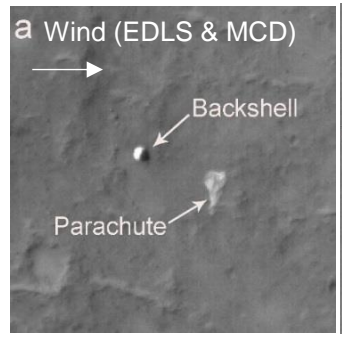

(b) Opportunity

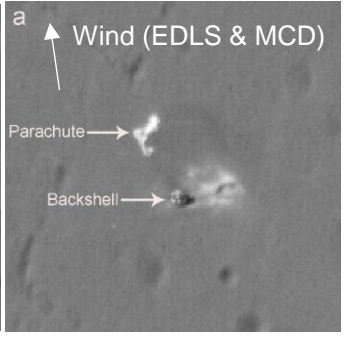

(c) Curiosity

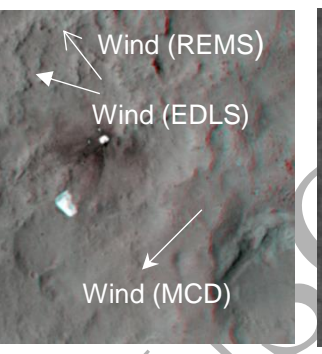

(d) Phoenix

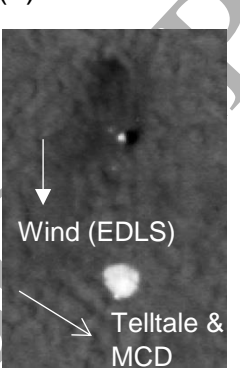

Figure 12: Parachute direction and canopy appearance.

561

562

563

564<smiles>[CH]1CC1</smiles>

agreement, which may be because wind speed is more sensitive to the thermal and mechanical turbulence in the PBL. The apparent high winds at the Phoenix site, turbulence during the landing of Viking lander 1 , together with a gust previously reported experienced by the Spirit rover, suggest underlying large eddies in the winds aloft in the PBL will need to be more fully characterised in the future.

\section{Acknowledgement}

AH acknowledges Finnish grant \#310509.

\section{References}

Bauske, R. (2004). Dependence of the Beagle2 Trajectory on the Mars Atmosphere. In 18 th International Symposium on Space Flight Dynamics (p. 577). volume 548 of ESA Special Publication.

Chamberlain, T. E., Cole, H. L., Dutton, R. G., Greene, G. C., \& Tillman, J. E. (1976). Atmospheric measurements on Mars - The Viking meteorology experiment. Bulletin of the American Meteorological Society, 57, 1094-1104.

Chapman, R. M., Lewis, S. R., Balme, M., \& Steele, L. J. (2017). Diurnal variation in martian dust devil activity. Icarus, 292, 154-167.

570 Cheng, Y., Goguen, J., Johnson, A., Leger, C., Matthies, L., Martin, M. S., \& Wilson, R. (2004). The Mars Exploration Rovers Descent Image Motion

572 Estimation System. IEEE Intelligent Systems, 19, 13-21. 
Cooley, C. G., \& Lewis, J. G. (1977). Viking lander system primary mission performance report. Martin Marietta.

Cruz, J. R., Mineck, R. E., Keller, D. F., \& Bobskill, M. V. (2003). Wind Tunnel Testing of Various Disk-Gap-Band Parachutes. In 17th AIAA Aerodynamics Decelerator Systems Technology Conference, 19-22 May 2003, Phoenix, AZ, United States.

Cruz, J. R., Way, D. W., Shidner, J. D., Davis, J. L., Adams, D. S., \& Kipp, D. M. (2014). Reconstruction of the Mars Science Laboratory Parachute Performance. Journal of Spacecraft and Rockets, 51, 1185-1196.

Day, M., \& Kocurek, G. (2016). Observations of an aeolian landscape: From surface to orbit in Gale Crater. Icarus, 280, 37-71.

Desai, P. N., \& Knocke, P. C. (2007). Mars exploration rovers entry, descent, and landing trajectory analysis. Journal of the Astronautical Sciences, 55, $311-323$.

Desai, P. N., Prince, J. L., Queen, E. M., Schoenenberger, M., Cruz, J. R., \& Grover, M. R. (2011). Entry, Descent, and Landing Performance of the Mars Phoenix Lander. Journal of Spacecraft and Rockets, 48, 798-808.

Dutta, S., \& Braun, R. D. (2014). Státistical Entry, Descent, and Landing Performance Reconstruction of the Mars Science Laboratory. Journal of Spacecraft and Rockets, 51, 1048-1061.

Ellehoj, M. D., Gunnlaugsson, H. P., Taylor, P. A., Kahanpää, H., Bean, K. M., Cantor, B. A., Gheynani, B. T., Drube, L., Fisher, D., Harri, A.-M., HolsteinRathlou, C., Lemmon, M. T., Madsen, M. B., Malin, M. C., Polkko, J., Smith, P. H., Tamppari, L. K., Weng, W., \& Whiteway, J. (2010). Convective vortices and dust devils at the Phoenix Mars mission landing site. Journal of Geophysical Research (Planets), 115, E00E16. doi:10.1029/2009JE003413.

Fallon, E. \& Sinclair, R. (2003). Design and Development of the Main Parachute for the Beagle 2 Mars Lander. In 17th AIAA Aerodynamic Decelerator Systems Technology Conference and Seminar. Monterey, California..

Ferri, F., Karatekin, O., Aboudan, A., VanHove, B., Colombatti, G., Bettanini, C., Debei, S., Gerbal, N., Lewis, S., \& Forget, F. (2017). Atmospheric Mars entry and landing investigation and analysis (AMELIA) by ExoMars 2016 Sciaparelli entry descent module. In Sixth International Workshop on thenMars Atmosphere: Modelling and Observations, 17-20 Jan 2017, Granada, Spain, CNES.

Gunnlaugsson, H. P., Holstein-Rathlou, C., Merrison, J. P., Knak Jensen, S., Lange, C. F., Larsen, S. E., Madsen, M. B., Nørnberg, P., Bechtold, H., Hald, E., Iversen, J. J., Lange, P., Lykkegaard, F., Rander, F., Lemmon, M., Renno, N., Taylor, P., \& Smith, P. (2008). Telltale wind indicator for 
the Mars Phoenix lander. Journal of Geophysical Research (Planets), 113, E00A04.

Haberle, R. M., Houben, H. C., Hertenstein, R., \& Herdtle, T. (1993). A boundary-layer model for Mars - Comparison with Viking lander and entry data. Journal of Atmospheric Sciences, 50, 1544-1559.

Hess, S. L., Henry, R. M., Leovy, C. B., Tillman, J. E., \& Ryan, J. A. (1977). Meteorological results from the surface of Mars - Viking 1 and 2. Journal of Geophysical Research, 82, 4559-4574.

Holstein-Rathlou, C., Maue, A., \& Withers, P. (2016). Atmospheric studies from the Mars Science Laboratory Entry, Descent and Landing atmospheric structure reconstruction. Planetary and Space Science, 120, 15-23.

Jackson, D. W. T., Bourke, M. C., \& Smyth, T. A. G. (2015). The dune effect on sand-transporting winds on Mars. Nature Communications, 6, 8796.

Justus, C. G., Duvall, A., \& Johnson, D. L. (2004). Mars-GRAM validation with Mars global surveyor data. Advances in Space Research, 34, 1673-1676.

Karatekin, ., \& Asmar, S. R. (2011). Entry trajectory reconstruction using Phoenix radio link: Deducing Martian wind velocities. In $I P P W-8$, Portsmouth, Virginia, 6-10 June 2011.

Kass, D. M., Kleinböhl, A., Schofield, J. T., McCleese, D. J., Mischna, M. A., \& McS Team (2008). MCS Views of the Northern Polar Atmosphere During Phoenix Approach. In Third International Workshop on The Mars Atmosphere: Modeling and Observations. volume 1447 of LPI Contributions.

Kauhanen, J., Siili, T., Jrvenoja, S., \& Savijrvi, H. (2008). The mars limited area model and simulations of atmospheric circulations for the phoenix landing area and season of operation. Journal of Geophysical Research: Planets, 113, n/a-n/a. URL: http://dx.doi.org/10.1029/2007JE003011. doi:10.1029/2007JE003011. E00A14.

Kutty, P. (2014). Reconstruction and uncertainty quantification of entry, descent and landing trajectories using vehicle aerodynamics. Georgia Institute of Technology, Masters Thesis.

Liu, Z. Y.-C., \& Zimbelman, J. R. (2015). Recent near-surface wind directions inferred from mapping sand ripples on Martian dunes. Icarus, 261, 169-181.

Lorenz, R. D., \& Jackson, B. K. (2016). Dust Devil Populations and Statistics. Space Science Review, 203, 277-297.

Martin, M. S., Mendeck, G. F., Brugarolas, P. B., Singh, G., Serricchio, F., Lee, S. W., Wong, E. C., \& Essmiller, J. C. (2015). In-flight experience of the Mars Science Laboratory Guidance, Navigation, and Control system for Entry, Descent, and Landing. CEAS Space Journal, 7, 119-142. 


\section{2}

683 Mo

McEwen, A. (2007). Mars Reconnaissance Orbiter High Resolution Imaging Science Experiment. MRO-M-HIRISE-2-EDR-V1.0, NASA Planetary Data System, .

Merrifield, J. (2015). Beagle 2 discovered. In UK Space Conference. Liverpool, $U K$.

Michaels, T. I., \& Rafkin, S. C. R. (2008). Meteorological predictions for candidate 2007 Phoenix Mars Lander sites using the Mars Regional Atmospheric Modeling System (MRAMS). Journal of Geophysical Research (Planets), 113, E00A07.

Millour, E., Forget, F., Gonzlez-Galindo, F., Spiga, A., Lebonnois, S., Lewis, S. R., Montabone, L., Read, P. L., Lpez-Valverde, M. A., Gilli, G., Lefvre, F., Montmessin, F., Desjean, M.-C., \& Huot, J.-P. (2009). The mars climate database (version 4.3). In SAE Technical Paper. SAE International.

Millour, E., Forget, F., \& Lewis, S. R. (2015). Mars Climate Database v5.2 user manual. Technical Report.

Montmessin, F. (2014). The MARs Boundary Layer Lidar experiment (MARBLL): Winds at last! In EGU General Assembly Conference Abstracts (p. 16617). volume 16 of EGU General Assembly Conference Abstracts.

Montmessin, F. (2017). The MARs Boundary Layer Lidar experiment (MARBLL): Winds at last! . In Exomars Atmospheric Science and Missions Workshop, Saariselka,Finland, 26-30 March.

Moores, J. E., Lemmon, M. T., Rafkin, S. C. R., Francis, R., Pla-Garcia, J., de la Torre Juárez, M., Bean, K., Kass, D., Haberle, R., Newman, C., Mischna, M., Vasavada, A., Rennó, N., Bell, J., Calef, F., Cantor, B., Mcconnochie, T. H., Harri, A.-M., Genzer, M., Wong, M., Smith, M. D., Javier Martín-Torres, F., Zorzano, M.-P., Kemppinen, O., \& McCullough, E. (2015). Atmospheric movies acquired at the Mars Science Laboratory landing site: Cloud morphology, frequency and significance to the Gale Crater water cycle and Phoenix mission results. Advances in Space Research, 55, 2217-2238. doi:10.1016/j.asr.2015.02.007.

Moores, J, E., Lemmon, M. T., Smith, P. H., Komguem, L., \& Whiteway, J. A. (2010). Atmospheric dynamics at the Phoenix landing site as seen by the Surface Stereo Imager. Journal of Geophysical Research, 115, E00E08.

Moores, J. E., Schieber, J., Kling, A. M., Haberle, R. M., Moore, C. A., Anderson, M. S., Katz, I., Yavrouian, A., Malin, M. C., Olson, T., Rafkin, S. C. R., Lemmon, M. T., Sullivan, R. J., Comeaux, K., \& Vasavada, A. R. (2016). Transient atmospheric effects of the landing of the Mars Science Laboratory rover: The emission and dissipation of dust and carbazic acid. Advances in Space Research, 58, 1066-1092. doi:10.1016/j.asr.2016.05.051. 
NASA (2008). Phoenix Landing: Mission to the Martian Polar North. NASA Press kit.

Parteli, E. J. R., Durán, O., Tsoar, H., Schwämmle, V., \& Herrmann, H. J. (2009). Dune formation under bimodal winds. Proceedings of the National Academy of Science, 106, 22085-22089.

Paton, M. (2017). Protection of surface assets on Mars from wind blown jettisoned spacecraft components. Acta Astronautica, 136, 395-406.

Petrosyan, A., Galperin, B., Larsen, S. E., Lewis, S. R., Määttänen, A., Read, P. L., Renno, N., Rogberg, L. P. H. T., Savijärvi, H., Siili, T., Spiga, A., Toigo, A., \& Vázquez, L. (2011). The Martian Atmospheric Boundary Layer. Reviews of Geophysics, 49, RG3005.

Savijärvi, H. (1995). Mars boundary layer modeling: Diurnal moisture cycle and soil properties at the Viking Lander 1 Site. Icarus, 117, 120-127.

Savijärvi, H. (1999). A model study of the atmospheric boundary layer in the Mars Pathfinder lander conditions. Quarterly Journal of the Royal Meteorological Society, 125, 483-493.

Savijärvi, H. (2012). Mechanisms of the diurnal cycle in the atmospheric boundary layer of Mars. Quarterly Journal of the Royal Meteorological Society, 138, 552-560. doi:10.1002/qj.930.

Savijärvi, H., Crisp, D., \& Harri, A.-M. (2005). Effects of CO2 and dust on present-day solar radiation and climate on Mars. Quarterly Journal of the Royal Meteorological Society, 131, 2907-2922.

Savijärvi, H., \& Kauhanen, J/ (2008). Surface and boundary-layer modelling for the Mars Exploration Rover sites. Quarterly Journal of the Royal Meteorological Society, 134, 635-641.

Savijärvi, H., \& Määttänen, A. (2010). Boundary-layer simulations for the Mars Phoenix lander site. Quarterly Journal of the Royal Meteorological Society, 136, 1497-1505.

Savijärvi, H., Määttänen, A., Kauhanen, J., \& Harri, A.-M. (2004). Mars Pathfinder: New data and new model simulations. Quarterly Journal of the Royal Meteorological Society, 130, 669-683.

Seiff, A. (1993a). Mars atmospheric winds indicated by motion of the Viking landers during parachute descent. Journal of Geophysical Research, 98, 74617474 .

Seiff, A. (1993b). Mars atmospheric winds indicated by motion of the Viking landers during parachute descent. Journal of Geophysical Research, 98, 74617474 . 
Seiff, A., \& Kirk, D. B. (1977). Structure of the atmosphere of Mars in summer at mid-latitudes. Journal of Geophysical Research, 82, 4364-4378.

Seiff, A., Tillman, J. E., Murphy, J. R., Schofield, J. T., Crisp, D., Barnes, J. R., LaBaw, C., Mahoney, C., Mihalov, J. D., Wilson, G. R., \& Haberle, R. (1997). The atmosphere structure and meteorology instrument on the Mars Pathfinder lander. Journal of Geophysical Research, 102, 4045-4056.

Smith, D. E., Zuber, M. T., Frey, H. V., Garvin, J. B., Head, J. W., Muhleman, D. O., Pettengill, G. H., Phillips, R. J., Solomon, S. C., Zwally, H. J., Banerdt, W. B., Duxbury, T. C., Golombek, M. P., Lemoine, F. G., Neumann, G. A., Rowlands, D. D., Aharonson, O., Ford, P. G., Ivanov, A. B., Johnson, C. L., McGovern, P. J., Abshire, J. B., Afzal, R. S., \& Sun, X. (2001). Mars Orbiter Laser Altimeter: Experiment summary after the first year of global mapping of Mars. Journal of Geophysical Research, 106, 23689-23722.

Spencer, D. A., Blanchard, R. C., Braun, R. D., Kallemeyn, P. H., \& Thurman, S. W. (1999). Mars pathfinder entry, descent, and landing reconstruction. Journal of Spacecraft and Rockets, 36, 357366.

Spiga, A., Barth, E., Gu, Z., Hoffmann, F., Ito, J., Jemmett-Smith, B., Klose, M., Nishizawa, S., Raasch, S., Rafkin, S., Takemi, T., Tyler, D., \& Wei, W. (2016). Large-Eddy Simulations of Dust Devils and Convective Vortices. Space Science Review, 203, 245-275.

Spiga, A., \& Lewis, S. R. (2010). Martian mesoscale and microscale wind variability of relevance for dust lifting. International Journal of Mars Science and Exploration, 5, 146-158.

Stanzel, C., Pätzold, M., Williams, D. A., Whelley, P. L., Greeley, R., Neukum, G., \& the HRSC Co-Investigator Team (2008). Dust devil speeds, directions of motion and general characteristics observed by the Mars Express High Resolution Stereo Camera. Icarus, 197, 39-51.

Szalai, C., Thoma, B., Lee, W., Maki, J., Wilcoxson, W. H., Venkatapathy, E., \& White, T. (2011). Mars exploration rover heatshield observation campaign. 42nd AIAA Thermophysics Conference, . doi:10.2514/6.2011-3956.

Tamppari, L. K., Bass, D., Cantor, B., Daubar, I., Dickinson, C., Fisher, D., Fujii, K., Gunnlauggson, H. P., Hudson, T. L., Kass, D., Kleinböhl, A., Komguem, L., Lemmon, M. T., Mellon, M., Moores, J., Pankine, A., Pathak, J., Searls, M., Seelos, F., Smith, M. D., Smrekar, S., Taylor, P., HolsteinRathlou, C., Weng, W., Whiteway, J., \& Wolff, M. (2010). Phoenix and MRO coordinated atmospheric measurements. Journal of Geophysical Research (Planets), 115, E00E17. doi:10.1029/2009JE003415.

Taylor, A. P. (2000). Design Optimization of the Beagle II Mars Lander Airbags Through Explicit Finite Element Analysis An Update. In 6th International LS-DYNA Conference, April 9-11, 2000, Dearborn, Michigan. 


$$
797 \mathrm{C}
$$
as $\theta$ and $p h i$ increases.

The equations of free motion without any lift or drag from interactions with the atmospheric flow are as follows:

$$
\frac{\partial^{2} r}{\partial t^{2}}=r\left(\frac{\partial \theta}{\partial t}\right)^{2}(\cos \phi)^{2}+r \frac{\partial \phi}{\partial t}-\frac{G M}{r^{2}}
$$


Table A.5: Vehicle and EDLS component properties.

\begin{tabular}{|c|c|c|c|c|c|c|c|c|c|}
\hline Parameter & VL-1 & VL-2 & $\mathrm{PF}$ & $\mathrm{B} 2$ & MER 1 & MER 2 & PHX & MSL & $\mathrm{SCH}$ \\
\hline \multicolumn{10}{|l|}{ Aeroshell } \\
\hline$L o D$ & 0.18 & 0.18 & 0 & 0 & 0 & 0 & 0.00 & 0.24 & 0 \\
\hline$m_{\text {entry }}(k g)$ & 977 & 977 & 585 & 69 & 827 & 832 & 602 & 3100 & 577 \\
\hline$C_{D}$ & 1.55 & 1.55 & 1.5 & 1.5 & 1.5 & 1.5 & 1.6 & 1.55 & 1.55 \\
\hline$L o D$ & 0.18 & 0.18 & 0 & 0 & 0 & 0 & 0.06 & 0.24 & 0 \\
\hline$d_{\text {aero }}(\mathrm{m})$ & 3.5 & 3.5 & 2.65 & 0.9 & 2.65 & & 2.65 & 4.5 & 2.4 \\
\hline$A_{\text {aero }}\left(\mathrm{m}^{2}\right)$ & 15 & 15 & 8 & 1 & 8 & 8 & 9 & 25 & 7 \\
\hline$\beta_{\text {aero }}\left(\mathrm{kg} \mathrm{m}^{-2}\right)$ & 66 & 66 & 71 & 72 & 100 & $101)$ & 65 & 126 & 82 \\
\hline \multicolumn{10}{|l|}{ Parachute deployed } \\
\hline$m_{\text {nosehield }}(\mathrm{kg})$ & 740 & 740 & 521 & 59 & & 754 & 511 & 2718 & 497 \\
\hline$d_{\text {chute }}(\mathrm{m})$ & 16 & 16 & 12.74 & 3,2 & 14.1 & 14.1 & 11.73 & 19.7 & 12 \\
\hline$C_{D}$ & 0.67 & 0.67 & 0.44 & & 0.6 & 0.6 & 0.6 & 0.6 & 0.6 \\
\hline$A_{\text {chute }}\left(\mathrm{m}^{2}\right)$ & 135 & 135 & 56 & & 69 & 69 & 49 & 139 & 45 \\
\hline$\beta_{\text {withshield }}\left(\mathrm{kg} \mathrm{m}^{-2}\right)$ & 7 & 7 & 10 & 17 & 9 & 9 & 9 & 17 & 10 \\
\hline$\beta_{\text {noshield }}\left(\mathrm{kg} \mathrm{m}^{-2}\right)$ & 5 & 5 & 9 & 15 & 8 & 8 & 8 & 15 & 9 \\
\hline \multicolumn{10}{|l|}{ Lander } \\
\hline$m_{\text {lander }}(\mathrm{kg})$ & 673 & 673 & 464 & 50 & 540 & 545 & 401 & 2369 & 477 \\
\hline$T(\mathrm{kN})$ & 2.1 & 2.1 & 16.7 & 0 & 22.4 & 22.4 & 3.6 & 24.9 & 3.6 \\
\hline$T / W\left(\mathrm{~N} \mathrm{~kg}^{-1}\right)$ & 3 & 3 & 36 & 0 & 41.5 & 41 & 9 & 10.5 & 7.5 \\
\hline \multicolumn{10}{|l|}{ Heat shield } \\
\hline$m_{\text {shield }}(\mathrm{kg})$ & & & 64.4 & 9.78 & 78 & 78 & 62 & 382 & 80 \\
\hline$C_{D}$ & & 1.0 & 1.0 & 1.0 & 1.0 & 1.0 & 1.0 & 1.0 & 1.0 \\
\hline$d_{\text {shield }}(\mathrm{m})$ & 3.5 & 3.5 & 2.65 & 0.9 & 2.65 & 2.65 & 2.65 & 4.5 & 2.4 \\
\hline$A_{\text {shield }}\left(\mathrm{m}^{2}\right)$ & 15 & 15 & 8 & 1 & 8 & 8 & 8.5 & 25 & 7 \\
\hline$\beta_{\text {shield }}\left(\mathrm{kg} \mathrm{m}^{-2}\right)$ & 25 & 25 & 12 & 15 & 14 & 14 & 11 & 24 & 18 \\
\hline \multicolumn{10}{|l|}{ Backshell } \\
\hline$m_{\text {back }}(\mathrm{kg})$ & 67 & 67 & 57 & 9.5 & 209 & 209 & 110 & 349 & 20 \\
\hline$\beta_{b a c k}$ & 0.5 & 0.5 & 1.0 & 2.4 & 3.0 & 3.0 & 2.2 & 2.5 & 0.4 \\
\hline \multicolumn{10}{|l|}{ Ringsail } \\
\hline$m_{\text {ring }}$ & & & & 1 & & & & & \\
\hline$D_{\text {ring }}$ & & & & 10 & & & & & \\
\hline$C_{D}$ & & & & 0.8 & & & & & \\
\hline$A_{\text {ring }}$ & & & & 62.8 & & & & & \\
\hline$\beta_{\text {ring }}$ & & & & 0.02 & & & & & \\
\hline$\beta_{w l}$ & & & & 1.25 & & & & & \\
\hline
\end{tabular}


Table A.6: Trajectory parameters values required for modelling and verification of the simulations.

\begin{tabular}{|c|c|c|c|c|c|c|c|c|c|}
\hline Parameter & VL-1 & VL-2 & $\mathrm{PF}$ & B2 & MER 1 & MER 2 & PHX & MSL & $\mathrm{SCH}$ \\
\hline \multicolumn{10}{|c|}{ Atmosphere parameters } \\
\hline$\rho_{\text {surf }}\left(\mathrm{kg} \mathrm{m}^{-3}\right)$ & 0.017 & 0.018 & $\mathrm{n} / \mathrm{a}$ & 0.019 & 0.015 & 0.013 & 0.022 & 0.014 & 0.014 \\
\hline$h_{a t m}(\mathrm{~km})$ & 10.0 & 10.0 & 10.0 & 10.0 & 10.0 & 10.0 & 10.0 & 10.0 & 10.0 \\
\hline \multicolumn{10}{|c|}{ Entry } \\
\hline$z_{\text {entry }}(\mathrm{km})$ & 242 & 242 & 207 & 120 & 130 & 128 & 130 & 125 & 121.5 \\
\hline$v_{\text {entry }}\left(\mathrm{km} \mathrm{s}^{-1}\right)$ & 4.7 & 4.7 & 7.4 & 5.6 & 5.6 & & $5.7^{\prime}$ & 5.8 & 5.7 \\
\hline$\gamma_{\text {entry }}(\mathrm{deg})$ & 17 & 17.1 & 16.9 & 16.6 & 11.5 & & 12.5 & 15.5 & 16 \\
\hline$\alpha_{\text {entry }}(\mathrm{deg})$ & 56 & 43 & 255 & 86 & 79 & 86.5 & 79 & 94 & 118 \\
\hline$\theta_{\text {entry }}(\mathrm{deg})$ & 298 & 117 & 344 & 83 & 162 & 341 & 200.5 & 127 & 343 \\
\hline$\phi_{\text {entry }}(\mathrm{deg})$ & 13 & 37 & 23 & 11 & -18 & -3 & 69 & -4 & 4 \\
\hline \multicolumn{10}{|c|}{ Parachute deployment } \\
\hline$z_{\text {chute }}(\mathrm{km})$ & 5.9 & 5.9 & 9.40 & 71 & 7.5 & 7.5 & 13.3 & 12.0 & 11.0 \\
\hline$v_{\text {chute }}\left(\mathrm{m} \mathrm{s}^{-1}\right)$ & 238 & 237 & 377 & 360 & 411 & 430 & 384 & 492 & 478 \\
\hline$\gamma_{\text {chute }}(\mathrm{deg})$ & -53.4 & -50.8 & -25.5 & -25.4 & -28.1 & -26.7 & -27.5 & -22.4 & -26.6 \\
\hline$\alpha_{\text {chute }}$ (deg) & 56 & 55 & 253 & 88 & 75 & 86 & 108 & 93 & 119 \\
\hline \multicolumn{10}{|c|}{ Heat shield jettison } \\
\hline$z_{\text {shield }}(\mathrm{km})$ & 4.5 & 4.6 & & 0.3 & 5.7 & 5.7 & 11 & 11 & 5 \\
\hline$t_{\text {shield }}(s)$ & 7 & 7 & & 20 & 20 & 20 & 15 & 20 & 20 \\
\hline$v_{\text {shield }}\left(\mathrm{m} \mathrm{s}^{-1}\right)$ & 115 & 115 & 100 & 100 & 100 & 100 & 123 & 100 & 100 \\
\hline \multicolumn{10}{|c|}{ Backshell and parachute jettison } \\
\hline$z_{\text {lander }}(\mathrm{km})$ & .46 & 1.44 & 0.02 & 0.03 & 0.02 & 0.02 & 0.93 & 1.66 & 1.20 \\
\hline$v_{\text {lander }}\left(\mathrm{m} \mathrm{s}^{-1}\right)$ & & & 100 & 100 & 100 & 100 & 100 & 100 & 100 \\
\hline$\theta_{\text {surf }}(\mathrm{deg})$ & & & 326 & 90 & 175 & 354 & 234 & 137 & 354 \\
\hline$\phi_{\text {surf }}(\mathrm{deg})$ & & 48 & 19 & 11.5 & -14.6 & -2 & 62 & -5 & -2 \\
\hline \multicolumn{10}{|c|}{ Beagle 2 main parachute } \\
\hline $\begin{array}{l}z_{\text {ring }}(\mathrm{km}) \\
v_{\text {ring }}\left(\mathrm{m} \mathrm{s}^{-1}\right)\end{array}$ & & & & $\begin{array}{r}2.6 \\
96\end{array}$ & & & & & \\
\hline
\end{tabular}

Table A.7: Uncertainty $(\sigma)$ on model input parameters.

Angle (deg)

Velocity $\left(\mathrm{m} \mathrm{s}^{-1}\right)$

Altitude (m)

Density (\%)

Heat shield drag coefficient (\%)

Parachute drag coefficient (\%)

VL-1 VL-2

\begin{tabular}{rrrrrrrr}
1 & 1 & 1 & 1 & 1 & 1 & 1 & 1 \\
1 & 1 & 1 & 1 & 1 & 12 & 0.1 & 1 \\
100 & 100 & 2000 & 1700 & 1800 & 238 & 75 & 100 \\
0.5 & 0.5 & 5.0 & 5.0 & 5.0 & 5.0 & 5.0 & 5.0 \\
5 & 5 & 5 & 5 & 5 & 5 & 5 & 5 \\
5 & 5 & 5 & 5 & 5 & 5 & 5 & 5 \\
\hline
\end{tabular}




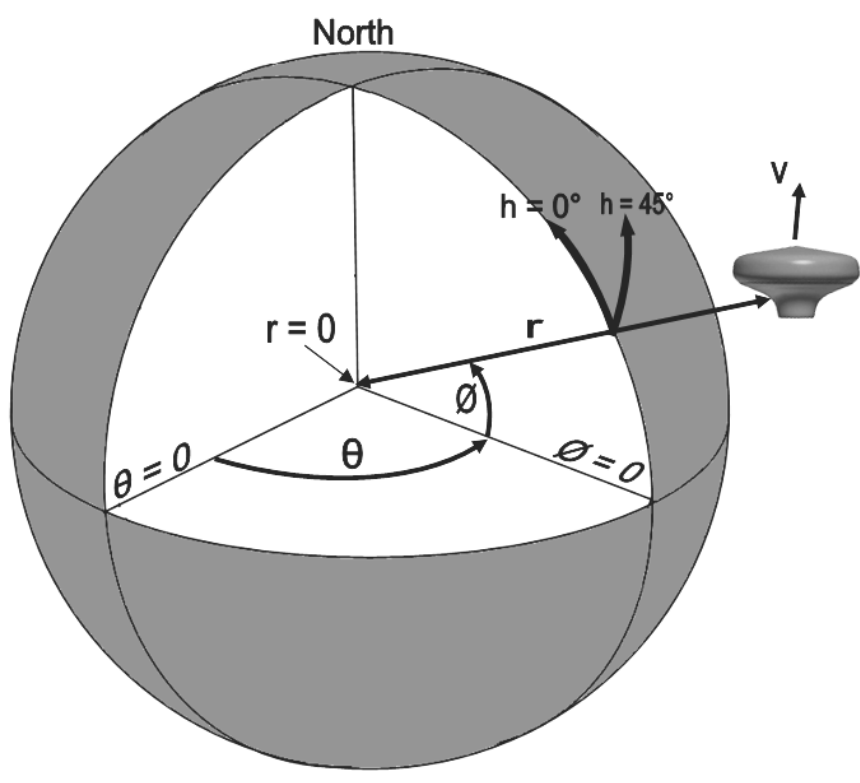

Figure B.13: Coordinate system used for trajectory modelling showing the important parameters used in the model and for interpreting the results.

$$
\begin{gathered}
\frac{\partial^{2} \theta}{\partial t^{2}}=2 \frac{\partial \theta}{\partial t} \frac{\partial \phi}{\partial t} \frac{\sin \phi}{\cos \theta}-\frac{2}{r} \frac{\partial r}{\partial t} \frac{\partial \theta}{\partial t} \\
\frac{\partial^{2} \phi}{\partial t^{2}}=-\left(\frac{\partial \theta}{\partial t}\right)^{2} \cos \phi \sin \phi-\frac{2}{r} \frac{\partial r}{\partial t} \frac{\partial \phi}{\partial t}
\end{gathered}
$$

Where $r$ is the radial distance from the centre of Mars, $\theta$ is the longitude, $\phi$ is the latitude, $\gamma$ is the flight path angle, $h$ is heading, $D$ is the drag force, $L$ is the lift force, $M$ is the mass of Mars, $G$ is the gravitational constant and $t$ is

Figure B13 and B14 show the essential parameters for modeling the motion of the vehicle through the atmosphere. The flight path angle $(\gamma)$ is the angle between the velocity vector (direction of motion) and the horizon. The angle of attack $(\alpha)$ is the angle between the long axis, in this case the direction the nose is pointing, and the velocity vector. Normally the angle of attack will remain constant for extended periods of time while the flight path angle will vary as aerodynamic forces effect its motion.

The equations used to calculate the lift and drag forces are:

$$
L=0.5 C_{L} \rho A v^{2}
$$



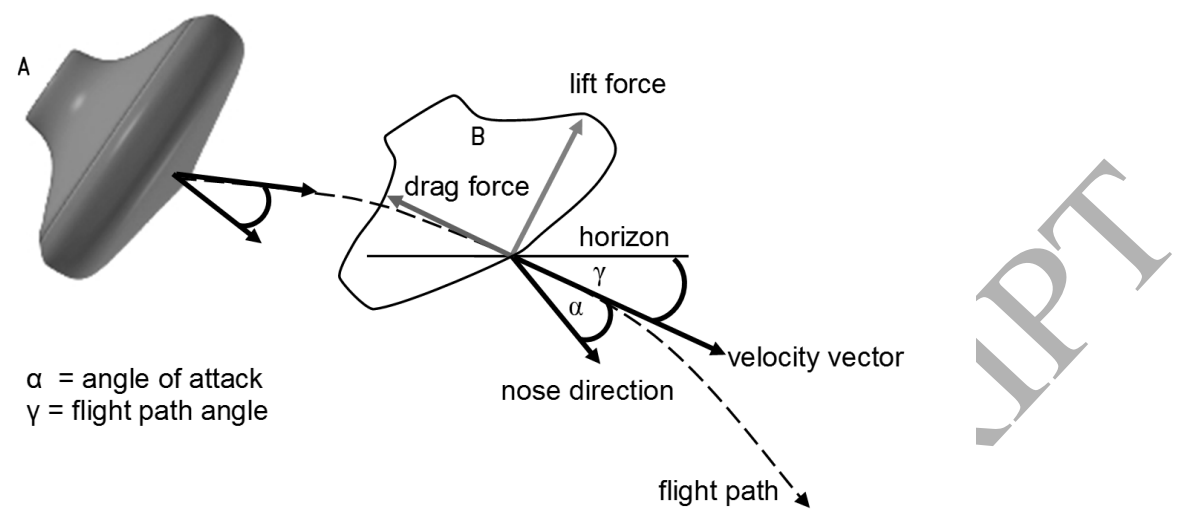

Figure B.14: Essential parameters for calculating the trajectory of a lifting body through the atmosphere.

$$
D=0.5 C_{D} \rho A v^{2}
$$

where $C_{L}$ is the lift coefficient, $C_{D}$ is the drag coefficient, $\rho$ is the density of the local atmosphere, $A$ is the reference area and $v$ is the velocity. The lift and drag coefficients can be measured directly in a wind tunnel or calculated using a model. These coefficients describe the airflow around the vehicle and are dependent on the angle of attack. The equations of motion for drag are as follows.

$$
\begin{gathered}
\frac{\partial^{2} r}{\partial t^{2}}=-\frac{D}{m} \sin (\gamma) \\
\frac{\partial^{2} \theta}{\partial t^{2}}=-\frac{D}{m} \frac{\cos (\gamma) \sin (h)}{r \cos (\phi)} \\
\frac{\partial^{2} \phi}{\partial t^{2}}=-\frac{D}{m} \frac{\cos (\gamma) \cos (h)}{r}
\end{gathered}
$$
${ }_{824}$ is defined as follows:

Similar equations are used to calculate lift but with a positive instead of a negative sign in front. The local atmospheric density can be calculated with varying level of complexity depending on the accuracy required. The atmosphere

$$
\rho=\exp (-z / H)
$$

where $H$ is the scale height. The force from the winds includes that from the rotation of the atmosphere. The bulk of the atmosphere is assumed to rotate ${ }_{827}$ at the same speed as the surface when there are no winds. For the zonal case 828 the wind is as follows. 


$$
v_{x}=v_{\text {surf }}+v_{\theta}
$$

\footnotetext{
2
}

where $v_{\text {surf }}$ is the speed of the surface and $v_{\theta}$ is the zonal wind relative to the bulk rotational motion of the atmosphere.

This would mean that a spacecraft dropped vertically into the planet's atmosphere at the equator would be decelerated horizontally even though the drag is assumed to act through the direction of motion. This is because the velocity used in the drag equations is as follows.

$$
v=\left(v_{x}+v_{y}+v_{z}\right)^{2}
$$

where $v_{x}$ is the longitudinal velocity, $v_{y}$ is the vertical velocity and $v_{z}$ is the latitudinal velocity. This approach makes sense for entry vehicles as they are designed to be dynamically stable, i.e. the centre of mass is in front of the centre of pressure, as the vehicle would reorientate itself to line up with the relative velocity vector of the wind.

The equations are solved numerically integrating with time.

\section{Appendix C. Displacement of jettisoned hardware by wind layers}

The characteristic response of the Viking lander on the parachute to a step change in the horizontal wind speed was shown by Seiff (1993a) to be characterised as an exponential acquisition of the wind speed by the lander. After correcting for a dimensionally inconsistent exponent in paper's equation A7 we have the following.

$$
\frac{v}{v_{w}}=1-e^{-\frac{g}{v_{e q}} t}
$$

where $v$ is the horizontal velocity of the object, $v_{w}$ is the horizontal wind velocity, $g$ is the acceleration due to gravity, $v_{e q}$ is the equilibrium descent velocity, i.e. terminal velocity, and $t$ is the time. Seiff (1993a) define the characteristic response time of the object, which is the time to acquire $1-e^{-1}$ or $63 \%$, of the step change in the horizontal wind speed, as follows.

$$
\tau=\frac{v_{e q}}{g}
$$

Figure C15 shows the displacement of a descending lander and its jettisoned hardware calculated using our model. In figure C15 (a) and (b) a two kilometre thick wind layer is located with its mid-point located at an altitude of $7000 \mathrm{~m}$. Throughout the wind layer the wind is blowing at a speed of $5 \mathrm{~m} \mathrm{~s}^{-1}$ from the west. Outside the wind layer the wind speed is set to zero.

In figure C15 (b) the heat shield takes a longer time than the lander on the parachute to respond to the changes in the wind speed. Equation $\mathrm{C} 2$ can be used to compare the response times of the two objects. In our model the heat shield is descending at approximately $76 \mathrm{~m} \mathrm{~s}^{-1}$ while the lander on the parachute is descending at approximately $60 \mathrm{~m} \mathrm{~s}^{-1}$. The characteristic response time are 

lander.

then 20 and $16 \mathrm{~s}$ for the heat shield and lander on the parachute respectively. These times are consistent with the acquisition of wind speeds by the heat shield and lander on the parachute as can be seen in figure C15 (b).

In figure $\mathrm{C} 15$ (c) and (d) a wind layer has been placed close to the surface in our model. The free flying lander, having jettisoned the parachute, descends through the layer using its rocket motors and is not affected by the winds. In contrast the parachute is significantly displaced from the lander by the winds as it has a low ballistic coefficient and hence a low descent velocity. In our model the jettisoned parachute descends with a terminal velocity of $27 \mathrm{~m} \mathrm{~s}^{-1}$ corresponding to a response time of about $7 \mathrm{~s}$ which is consistent with figure C15 (d). The heat shield is only weakly deflected from its vertical patch by the wind layer due to its large ballistic coefficient and resulting high descent speed.

Some important conclusions regarding the analysis of displaced hardware can be drawn from the calculations in this section. The response times of the jettisoned hardware suggest a full trajectory model is required for measuring the wind speeds rather than relying on approximate calculation that assume the objects instantaneously acquire the wind speed. For example close to the surface, where the object may not have time to acquire the wind speed, a wind layer will produce different separation distances to a layer of the same thickness but at a higher altitude.

It is somewhat obvious that a jettisoned parachute will be increasingly displaced from the lander by stronger winds during its descent, i.e. for higher winds speeds but constant wind direction. When considering the jettisoned heat shield it may not be immediately obvious that a stronger wind will decrease the separation distance between the lander and heat shield. For example see figure C15 (a) for the case where there is a tail wind. This results in a decrease in separation distance compared to the no wind case, i.e. $\mathrm{A}<\mathrm{B}$. The lander on the lander on the parachute is blown closer to the heat shield.

\section{Appendix D. Impact/ocations for a jettisoned heat shield}

After the parachute has been deployed the lander begins to rapidly turn towards the vertical. At some time after the parachute has been deployed and before the lander has completed its turn into a vertical descent the heat shield is jettisoned. See table A5 for jettison angles and timer settings for each lander. If there are no winds a jettisoned heat shield will impact the surface at some point downrange from the lander due to its high ballistic coefficient and its horizontal velocity component upon being jettisoned. For a vehicle approaching from the north-west as with the Phoenix case the impact point will be south-west of the

The displaced heat shield impact point due to winds will be directly related to the magnitude and direction of the winds during the descent. In figure C16 shows the displacement of a heat shield with a nominal drag coefficient by winds from different directions. The displacement of the parachute due to winds is also shown for comparison. 
(a) Displacement by a high altitude wind layer

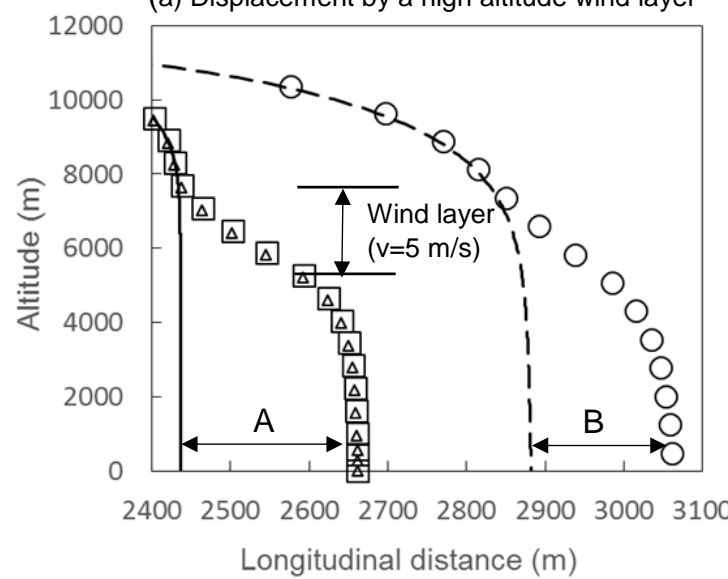

(c) Displacement by a low altitude wind layer

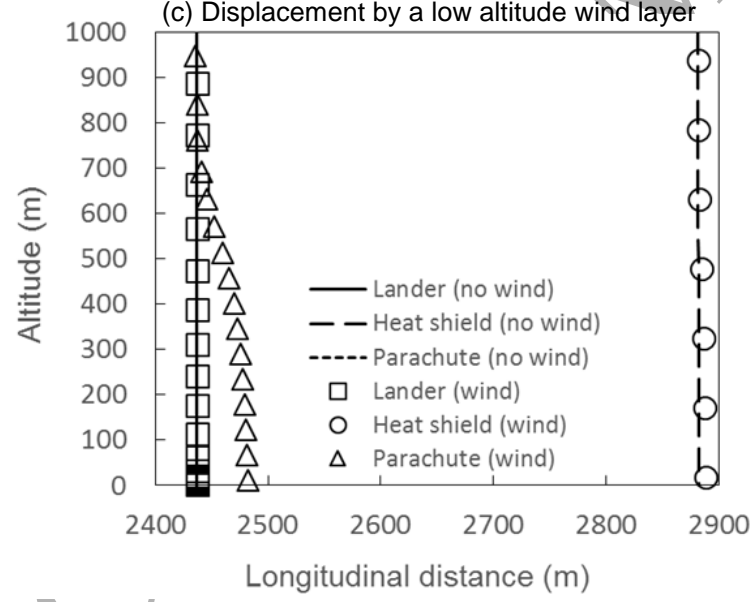

(b) Velocity in (a)

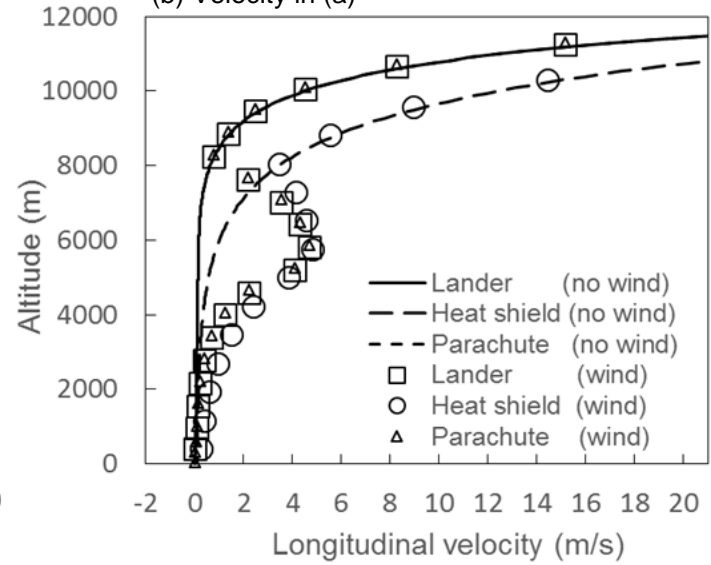

(d) Velocity in (c)

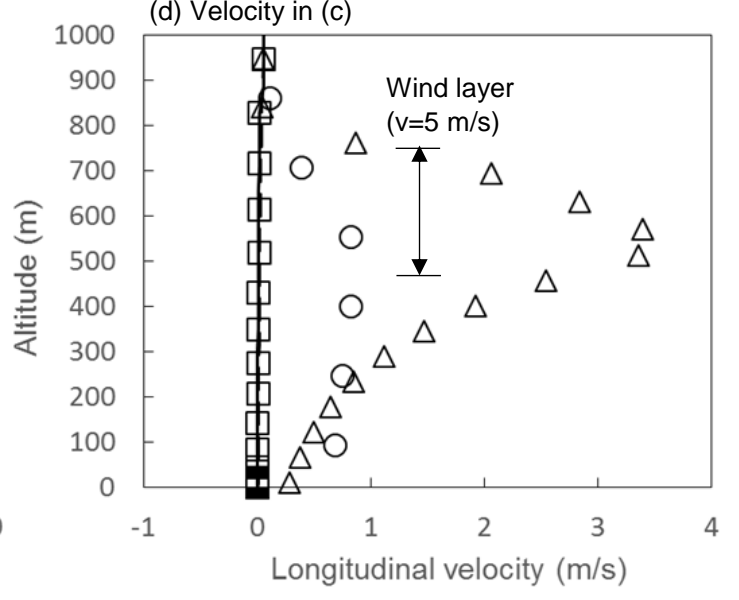

Figure C.15: Wind layers and their affect on the trajectory. 
(a) wind speed $=2 \mathrm{~m} \mathrm{~s}^{-1}$

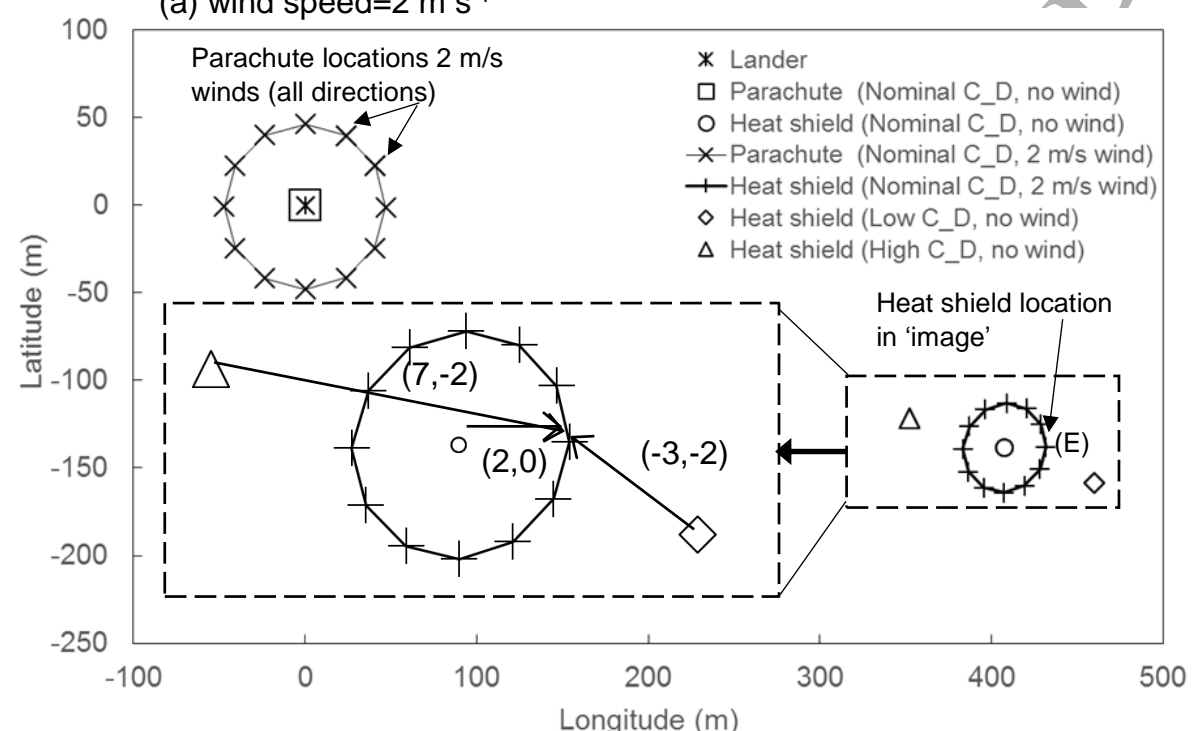

(b) wind speed $=10 \mathrm{~m} \mathrm{~s}^{-1}$

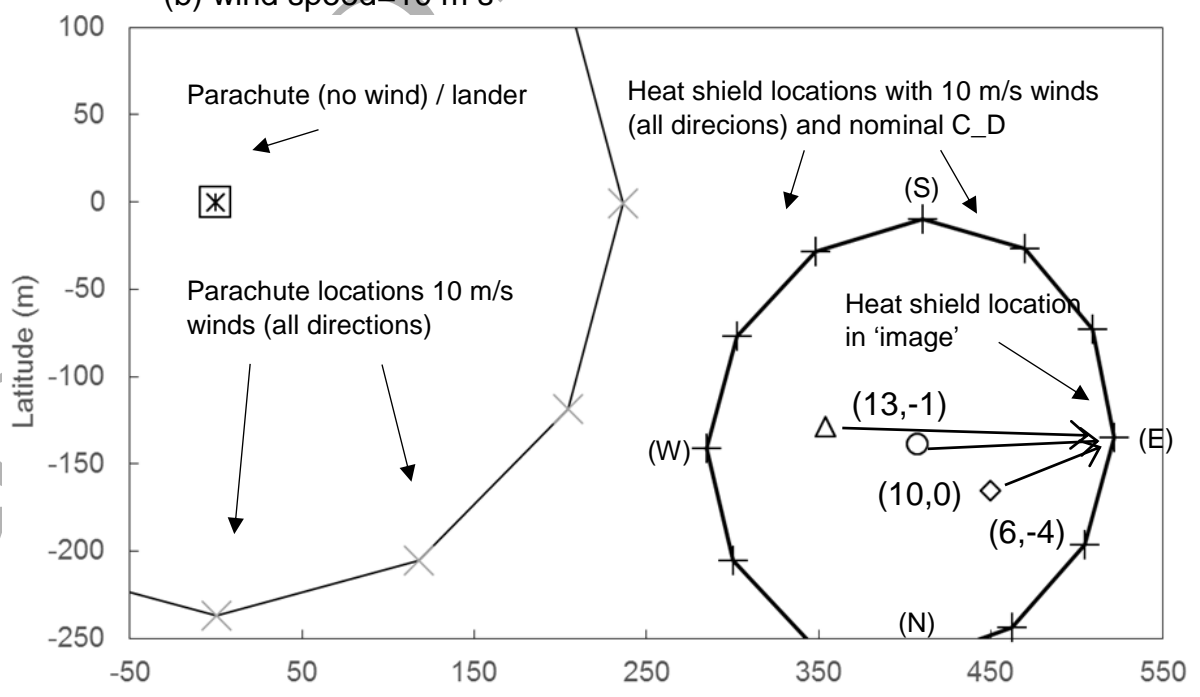

Figure D.16: Predicted impact locations the heat shield due to winds and uncertainty on its drag coefficient. 
As the impact points of the heat shield are directly related to the winds it is possible to visualise, in terms of location, the influence of the heat shield uncertainty on the measurements. Figure C16 shows the impact locations of the heat shield for high and low 3 sigma drag coefficients. If we assume one of the impact locations due to winds as a reference case then it can seen that a model, initialised with a high or low 3 sigma uncertainty, will produce larger uncertainties in direction (see arrows in figure C16) when weaker winds are blowing, i.e. the model will calculate nearly opposite wind directions for low and high 3 sigma uncertainties (also see figure 7).

If the winds are weak then a heat shield with a low drag coefficient will overshoot the observed heat shield impact location while a heat shield with a high drag coefficient will undershoot this point. When this situation arises the model will calculate winds in opposite directions eventually reaching a total uncertainty on the wind direction of 180 degrees. Wind direction uncertainty can be seen to reverse increases to more than $90^{\circ}$ below a wind speed of $4 \mathrm{~m}$ $\mathrm{s}^{-1}$. 